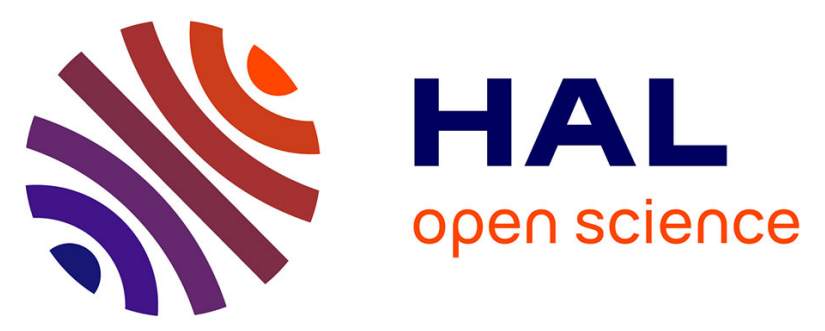

\title{
Dynamic 23Na MRI - A non-invasive window on neuroglial-vascular mechanisms underlying brain function
}

\author{
Mark Bydder, W Zaaraoui, Ben Ridley, Manon Soubrier, Marie Bertinetti, \\ Sylviane Confort-Gouny, Lothar Schad, Maxime Guye, Jean-Philippe Ranjeva
}

\section{To cite this version:}

Mark Bydder, W Zaaraoui, Ben Ridley, Manon Soubrier, Marie Bertinetti, et al.. Dynamic 23Na MRI - A non-invasive window on neuroglial-vascular mechanisms underlying brain function. NeuroImage, 2019, 184, pp.771-780. 10.1016/j.neuroimage.2018.09.071 . hal-02059518

\section{HAL Id: hal-02059518 \\ https://hal-amu.archives-ouvertes.fr/hal-02059518}

Submitted on 6 Mar 2019

HAL is a multi-disciplinary open access archive for the deposit and dissemination of scientific research documents, whether they are published or not. The documents may come from teaching and research institutions in France or abroad, or from public or private research centers.
L'archive ouverte pluridisciplinaire HAL, est destinée au dépôt et à la diffusion de documents scientifiques de niveau recherche, publiés ou non, émanant des établissements d'enseignement et de recherche français ou étrangers, des laboratoires publics ou privés.

\section{(c)(1)}

Distributed under a Creative Commons Attribution| 4.0 International License 


\section{Dynamic ${ }^{23} \mathrm{Na}$ MRI - a non-invasive window on neuroglial-vascular mechanisms}

underlying brain function

Mark Bydder ${ }^{1,2}$, Wafaa Zaaraoui ${ }^{1,2}$, Ben Ridley ${ }^{1,2}$, Manon Soubrier ${ }^{1,2}$, Marie Bertinetti ${ }^{1,2}$ Sylviane ConfortGouny $^{1,2}$, Lothar Schad ${ }^{3}$, Maxime Guye ${ }^{1,2}$, Jean-Philippe Ranjeva ${ }^{1,2^{*}}$

1. Aix-Marseille Univ, CNRS, CRMBM, Marseille, France

2. APHM, University Hospital Timone, CEMEREM, Marseille, France

3. Computer Assisted Clinical Medicine, Centre for Biomedicine and Medical Technology Mannheim, Heidelberg University, Mannheim, Germany

*Correspondence: Pr. Jean-Philippe Ranjeva

e-mail: jean-philippe.ranjeva@univ-amu.fr

Address: CRMBM, AMU-CNRS 7339,

Faculté de Médecine, 27 Boulevard Jean Moulin,

F-13385, Marseille, France

Key words: fMRI, Sodium, ${ }^{23} \mathrm{Na}$ MRI, Brain, Excitation, Inhibition, 7T, Motor system

Reference : Dynamic ${ }^{23} \mathrm{Na}$ MRI - A non-invasive window on neuroglial-vascular mechanisms underlying brain function.

Bydder M, Zaaraoui W, Ridley B, Soubrier M, Bertinetti M, Confort-Gouny S, Schad L, Guye M, Ranjeva JP. Neuroimage. 2019 Jan 1;184:771-780. doi:10.1016/j.neuroimage.2018.09.071.

\section{Abstract:}

A novel magnetic resonance imaging (MRI) acquisition and reconstruction method for obtaining a series of

dynamic sodium ${ }^{23} \mathrm{Na}$-MRI acquisitions was designed to non-invasively assess the signal variations of brain sodium during a hand motor task in 14 healthy human volunteers on an ultra high field (7T) MR scanner. Regions undergoing activation and deactivation were identified with reference to conventional task-related BOLD functional MRI (fMRI). Activation observed in the left central regions, the supplementary motor areas and the left cerebellum induced an increase in the sodium signal observed at ultra short echo time and a decrease in the ${ }^{23} \mathrm{Na}$ signal observed at long echo time. Based on a simple model of two distinct sodium pools (namely, restricted and mobile sodium), the ultra short echo time measures the totality of sodium whereas the long echo time is mainly sensitive to mobile sodium. This activation pattern is consistent with previously described processes related to an influx of $\mathrm{Na}^{+}$into the intracellular compartments and a moderate increase in the cerebral blood volume (CBV). In contrast, deactivation observed in the right central regions ipsilateral to the movement, the precuneus and the left cerebellum induced a slight decrease in sodium signal at ultra short echo time and an increase of sodium signal at longer echo times. This inhibitory pattern is compatible with a slight decrease in $\mathrm{CBV}$ and an efflux of intracellular $\mathrm{Na}^{+}$to the extracellular compartments that may reflect neural dendritic spine and astrocytic shrinkage, and an increase of sodium in the extracellular fraction. In conclusion, cerebral dynamic ${ }^{23} \mathrm{Na}$ MRI experiments can provide access to the ionic transients following a functional task occurring within the neuro-glial-vascular ensemble. This has the potential to open up a novel non-invasive window on the mechanisms underlying brain function. 


\section{Introduction}

Since its introduction in 1990 (Ogawa et al., 1990), functional magnetic resonance imaging (fMRI) has become an indispensable tool in neuroscience, providing insight into not only the localisation and organization of human brain function and task-related reorganization, but also the intrinsic factors underling its integration in task and rest states, and their evolution over time (Shine et al., 2016). However, the contrast mechanism in fMRI - the blood oxygen-level dependent (BOLD) effect - is an indirect report of fluctuations in neural activity, a fact that may be especially important in pathological states (e.g. epilepsy) where neurovascular decoupling is a common feature (Ridley et al., 2017b). Modelling efforts have endeavoured to provide more detailed accounts of the relationship between neuronal activity and functional hyperaemia ${ }^{4}$, including processes occurring in the microvasculature at the capillary level in terms of active dilation of pericytes (Hall et al., 2014). The metabolic and ionic elements of this phenomenon are also active fields of research. Recently, correlations were found between vesselspecific fMRI and intracellular calcium signal measured in neighboring neurons in anesthetized rats, linking neuronal activity to intrinsic oscillations in the cerebral vasculature, with a spatial correlation length of about $2 \mathrm{~mm}$ for arterioles (He et al., 2018). Sten and co-workers proposed a mechanistic model describing the balance between the excitatory and inhibitory inputs of glutamate and GABA to characterize not only the positive BOLD response (Lundengard et al., 2016) but also the negative BOLD response, stressing the crucial role of glutamate and GABA on astrocytic $\left[\mathrm{Ca}^{2+}\right]$ influx following neuronal excitation or inhibition (Sten et al., 2017). Following neuronal excitation, the release of the neurotransmitter glutamate by neurons in the synaptic cleft is also followed by its $\mathrm{Na}^{+}$-dependent clearance performed mainly by astrocytes (Chatton et al., 2016). Indeed, the dynamic changes in intracellular $\left[\mathrm{Na}^{+}\right]$represent new signalling elements in the brain, representing a more direct form of glial ionic excitability (Rose and Chatton, 2016).

Given this context, sodium $\left({ }^{23} \mathrm{Na}\right) \mathrm{MRI}$ offers a unique method for monitoring sodium signal variations in vivo and in a non-invasive manner. A number of studies have provided impressive demonstrations of the potential of brain ${ }^{23} \mathrm{Na}$ MRI to non-invasively detect accumulations of total sodium concentrations (TSC) in neurological disorders and diseases such as brain tumours (Thulborn et al., 2009), stroke (Hussain et al., 2009), Huntington's disease (Reetz et al., 2012), Alzheimer disease (Mellon et al., 2009), different phenotypes of Multiple Sclerosis (Inglese et al., 2010) (Zaaraoui et al., 2012) (Maarouf et al., 2017) and sodium abnormalities in partial epilepsy (Ridley et al., 2017a). However, all approaches employed to date suffer from poor temporal resolution (15-30 $\mathrm{min}$ ) and have thus far permitted only acquisition of static ${ }^{23} \mathrm{Na}$ MR images. This leaves unaddressed the characterisation of brain sodium dynamics. Such dynamics are of potentially great importance given the role of ${ }^{23} \mathrm{Na}$ in the transmembrane gradients that underlie, modulate and participate in neural activity, as well as the signals that instigate activity and the neuroenergetic pathways that power it (Chatton et al., 2016) (Madelin et al., 2014) (Thulborn, 2016).

Here, we propose new methodology that enables the dynamic exploration of variations in sodium signals during brain activation/inhibition. This approach consists of the combination of i) efficient acquisition schemes (radial density adapted sequences) (Nagel et al., 2009) and ultra high field MRI (7 Tesla) to counter the poor sensitivity inherent to ${ }^{23} \mathrm{Na}$, ii) a multi-TE approach to modulate the contributions of ${ }^{23} \mathrm{Na}$ signals from various brain environments (i.e. restricted and mobile pools) (Rooney and Springer, 1991) (Ridley et al., 2018) and iii) a weighted least squares sliding window reconstruction method to 
extract sub-30 second temporal information from an extended total acquisition time $(\mathrm{TA}=20 \mathrm{~min})$. This innovation was applied to characterize variation in sodium signals following excitation/inhibition processes induced by a conventional right-hand motor task in human volunteers, and in particular the consequences on ${ }^{23} \mathrm{Na}$ MRI signal of the variations in the proportions of sodium belonging to different environments (i.e. free isotropic environment as a hydrated ion or anisotropic and macromolecular environment as 'trapped' ion) within the neuro-gliavascular ensemble (Jolivet et al., 2015).

\section{Materials and Methods}

Subjects: Fourteen right-handed healthy volunteers (7 women/7 men, median age 21 years range [19y-39y]) were included in the protocol. Participants provided informed consent in compliance with the ethical requirements of the Declaration of Helsinki and the protocol was approved by the local Ethics Committee (Comité de Protection des Personnes sud Méditerranée 2).

${ }^{l}$ H MRI acquisition: Acquisitions were performed on a Magnetom 7T MR system (Siemens, Erlangen, Germany).

BOLD fMRI was performed using a ${ }^{1} \mathrm{H} 1 \mathrm{Tx} / 32 \mathrm{Rx}$ Nova head coil allowing parallel imaging using a multiband GE-EPI sequence $(\mathrm{MB}=5$, Grappa 2, $\mathrm{TE}=22 \mathrm{~ms}, \mathrm{TR}=1000 \mathrm{~ms}, 128$ phase encoding, true echo spacing $=0.64 \mathrm{~ms}, 85$ slices, voxels $\left.(1.6 \mathrm{~mm})^{3}\right)$. ${ }^{23} \mathrm{Na}$ MRI acquisition and reconstruction: Dynamic ${ }^{23} \mathrm{Na}$ MRI was conducted using a dual tuned QED $\left({ }^{23} \mathrm{Na} /{ }^{1} \mathrm{H}\right) \quad 1 \mathrm{~T}_{\mathrm{x}} / 1 \mathrm{R}_{\mathrm{x}}$ volumic birdcage coil enabling shimming on the proton signal and acquiring the ${ }^{23} \mathrm{Na}$ signal. ${ }^{23} \mathrm{Na}$ MRI was acquired with a triple-echo 3Dcenter-out radial ${ }^{23} \mathrm{Na} \quad \mathrm{MR}$ sequence $\left(\mathrm{TE}_{1} / \mathrm{TE}_{2} / \mathrm{TE}_{3}=0.2 \mathrm{~ms} / 10 \mathrm{~ms} / 19 \mathrm{~ms}, \quad \mathrm{TR}=120 \mathrm{~ms}, \quad \mathrm{BW}\right.$ $280 \mathrm{~Hz} /$ pixel, density adapted $\left(\mathrm{t}_{0}=500 \mathrm{us}\right), 10080$ spokes, $(3.5 \mathrm{~mm})^{3}$ nominal isotropic voxel (Nagel et al., 2009). In order to include temporal dynamics into the whole dataset of the triple-echo 3D-Density adapted radial ${ }^{23} \mathrm{Na}$ MRI sequence (Figure 1a) the 10080 projections comprising the full k-space (Figure 1b) were acquired in 42 consecutive series of 240 projections, each series describing a full polar geometric k-space coverage (Figure 1c). The 240 radial spokes composing each k-space set were acquired using a golden angle approach to homogeneously sample k-space every 30 s. Thus, each under-sampled k-space set was composed not only by low (center) but also high (external part) k-space frequencies with a point spread function (PSF) of $7.84 \mathrm{~mm}$ at $\mathrm{TE}=0.2 \mathrm{~ms}$ (Supplemental Figure 1a). The next set of 240 spokes was acquired with a small angular shift compared to the previous one. The whole k-space sampling (10080 projections) obtained in 20min10s was characterized by a PSF FWHM of $6.27 \mathrm{~mm}$. A non-uniform fast Fourier transform (NUFFT) reconstruction was implemented that uses weighted least squares to effectively share the high spatial frequencies from all interleaves but uses the low spatial frequencies from a single interleave. This procedure weighted each series of 240 projections by a factor of 100 , and set the others to 1 , to obtain 42 ${ }^{23} \mathrm{Na}$ MRI brain volumes for each TE with an effective temporal resolution of $30 \mathrm{~s}$ each (Figures $1 \mathrm{~d}, \mathrm{e}, \mathrm{f}$ ). The final ${ }^{23} \mathrm{Na}$ MRI volumes with a temporal resolution of $30 \mathrm{~s}$ had a PSF $_{\mathrm{FWHM}}$ of $6.34 \mathrm{~mm}$ (Supplemental Figure $1 b)$, very closed to the non-weighted whole k-space acquisition $\left(\mathrm{PSF}_{\mathrm{FWHM}}=6.27 \mathrm{~mm}\right.$, Supplemental Figure 1c).

The online reconstruction was performed using the Gadgetron platform (Xue et al., 2015) enabling the synchronization of the online scanner reconstructor to external computers for the efficient running of bespoke reconstruction procedures in Matlab (Natick, MA). Reconstructions were based on preconditioned conjugate gradient with forward- and adjunct-NUFFT transforms (Kaiser Bessel convolution kernel width 4)(Fessler, 2007). Our implementation is available at 
https://github.com/marcsous/nufft_3d).

To validate the approach, phantom experiments were performed using different flip angles on alternate interleaves $\left(90^{\circ}-90^{\circ} ; 90^{\circ}-88^{\circ}, 90^{\circ}-85^{\circ}, 90^{\circ}-80^{\circ}, 90^{\circ}\right.$ $75^{\circ}$ ) in order to mimic dynamic signal variations. To provide a reference standard for the true signal, full acquisitions were acquired at each flip angle separately.

\section{Differentiation of ${ }^{23} \mathrm{Na}$ signals from different brain} environments using multi-TE ${ }^{23} \mathrm{Na}$ MRI

While ${ }^{23} \mathrm{Na}$ MRI is mainly characterized by the bi-exponential signal decay, residual quadripole interactions can also occur. The quadripolar sodium nucleus is subject to the influence of fluctuations in neighbouring electric fields due to net positive and non-uniform distribution of charge. In isotropic or highly motile environments such as plasma or cerebrospinal fluid $(\mathrm{CSF})$, the correlation time $\left(\tau_{\mathrm{C}}\right)$ is much shorter than the Larmor period $\left(\omega_{0}{ }^{-1}\right)\left(\omega_{0} \cdot \tau_{C}\right.$ $\ll 1)$, leading to monoexponential longitudinal $\left(\mathrm{T}_{1}\right)$ and transverse $\left(\mathrm{T}_{2}\right)$ relaxation and no residual quadripole interaction. However, in tissue environments such as within cells or interstitial spaces between cells, the diffusion is restricted by the ${ }^{23} \mathrm{Na}$ cation interactions with macromolecular anions that produce residual quadripolar interactions and modulate decay behaviour with the satellite transitions that are subject to additional fast relaxation processes so that both $T_{1}$ and $T_{2}$ reflect biexponential decay (Rooney, Springer, NMR Biomed 1991) (Stobbe and Beaulieu, 2016) (Thulborn, 2016). Relative to the long TR and the previous in vivo measurements performed with 24 TEs (Ridley et al., 2018), the sodium signals in brain MRI have been modeled according to a simple bi-exponential $\mathrm{T}_{2} *$ decay, that was considered in first approximation as reflective of variations in tissue structure and physiology (cell/fibre density, fluid content etc) (Ridley et al., 2018) as well as

reflecting the extent of mobility/restrictiveness of different sodium brain environments.

In this basic framework while all environments contribute to observed signal, the dynamic information available using a multi-echo 3D-Density Adapted radial ${ }^{23} \mathrm{Na} \mathrm{MRI}$ sequence implies differential contributions of pools of sodium when sampled with TEs of different lengths. ${ }^{23} \mathrm{Na}$ MRI at $\mathrm{TE}_{1}=0.2 \mathrm{~ms}$ (ultra short) should provide a measurement of the total sodium signal (arising from all environments - mobile and restricted pools), while longer echoes $\left(\mathrm{TE}_{2}=10 \mathrm{~ms}\right.$ and $\mathrm{TE}_{3}=19 \mathrm{~ms}$ ) should be dominated by/weighted towards sodium from mobile pools (blood and CSF compartments) in relation to their long $\mathrm{T}_{2} *$ (Figure 2). Signals from the more restricted pool of sodium (mainly intra-cellular sodium but also limited contribution of restricted extracellular sodium) may be derived from the two other signals (see the green curve, Figure 2).

\section{Functional experiments:}

BOLD fMRI: A conventional right hand opposite finger tapping task was performed with alternation of resting-activation periods every 20s for BOLD fMRI (20 rest - 20 activation; $x 5$ times; $T A=3 \min 20$ ) A right hand motor task paradigm ( 5 periods of alternating rest-activation) was conducted on 14 healthy volunteers using BOLD fMRI at $7 \mathrm{~T}$ using the Multiband GE-EPI sequence proposed by the HCP consortium (Vu et al., 2017).

Conventional post-processing of BOLD EPI images including slice timing, realignment and spatial normalization (SPM12, Welcome Trust) was applied. Spatial normalization was performed on the EPI volumes using mutual information affine registration with the tissue probability maps of SPM12. Finally, general linear models were applied (first and second levels, One sample t-test $\mathrm{p}<0.005, \mathrm{k}=5$, FDR corrected $\mathrm{p}<0.05)$. 
${ }^{23} \mathrm{Na}$ fMRI: The functional paradigm was adapted to the low temporal resolution of dynamic ${ }^{23} \mathrm{Na}$ MRI with alternation of 1 rest - 1 active period of 30 s each repeated 21 times (total acquisition time $=21 \mathrm{~min}$ ). The time series of $\mathrm{Na}$ images were first denoised using a Rician filter (https://www.irisa.fr/visages/benchmarks). Then, postprocessing included realignment, spatial normalization and smoothing (FWHM=8mm) (SPM12, Wellcome Institute, London, UK). Spatial normalization was performed on the shortest TE ${ }^{23} \mathrm{Na}$ MRI volumes using mutual information affine registration with the tissue probability maps of SPM12 and the transformation was applied to all remaining ${ }^{23} \mathrm{Na} \mathrm{MRI}$ volumes. The hand motion paradigm was entered in a GLM model (with a gamma function of $25 \mathrm{~s}$ width) and voxel-wise analyses were applied (One sample ttest, $\mathrm{p}<0.02, \mathrm{k}=10, \quad$ FDRcorr $\mathrm{p}<0.05, \quad \mathrm{SPM} 12$, Supplemental Figures 3,4,5). Regional analyses of ${ }^{23} \mathrm{Na}$ signal variations were then performed in four regions of interest of the motor system showing positive and negative BOLD contrast. The anatomical definition was performed using the Neuromorphometrics atlas (SPM12) to quantify clusters of ${ }^{23} \mathrm{Na}$ signal variations of the Left and the Right Central Areas (included labels: pre- + post central gyri), and the Left and the Right Cerebellum (labels: Cerebellum exterior + Cerebellum White Matter + Cerebellar Vermal lobules I-V + Cerebellar Vermal lobules VI-VII + Cerebellar Vermal lobules VIII-X).

Wilcoxon tests were used to test the significance of $\mathrm{Z}$ score variations compared to a reference value of 0 $(\mathrm{p}<0.05$ corrected for the four comparisons corresponding to the 4 contrasts, $\mathrm{p}<0.0125)$.

\section{Results}

Coding of temporal information using dynamic ${ }^{23} \mathrm{Na}$

\section{MRI series}

Temporal sensitivity of dynamic ${ }^{23} \mathrm{Na}$ MRI reconstruction was validated on a phantom by alternating flip angles every 30 s to mimic a functional task and by performing the dynamic reconstruction described above (Figure 3). Phantom validation experiments produced time series that accurately tracked the flip angle changes. In relation to the true signal measured from separate acquisitions, approximately $80 \%$ of the available signal variation was captured by the dynamic technique. Synthetic data showed that the point spread function of the temporally resolved acquisition was very similar to the complete k-space acquisition (Supplemental Figure 1).

In the human brain, time-resolved ${ }^{23} \mathrm{Na} \mathrm{MRI}$ volumes obtained were very close in quality to the full sampled dataset but with an acquisition window corresponding to only one interleave (Figures $1 d, e, f)$. In addition the spatial smoothing of $8 \mathrm{~mm}$ used to fulfil the Gaussian field theory for voxel-wise statistical mapping analyses constrained spatial resolution to be similar for the different TEs.

\section{BOLD fMRI activation pattern following the right}

\section{hand motor task in healthy volunteers}

Positive BOLD contrast (activation) was observed in the left pre- and post- central areas, the bilateral cerebellum and the supplementary motor areas (SMA) (Figure 4a) and negative BOLD contrast (deactivation) within the right pre-and post-central regions, the precuneus and the left cerebellum (Figure 4b).

\section{${ }^{23} \mathrm{Na}$ signal variations in the BOLD activated regions}

As the primary goal was to characterize sodium variations in regions with significant BOLD variations, we studied ${ }^{23} \mathrm{Na}$ MRI signal variations in the motor areas with significant clusters observed on BOLD fMRI, namely the bilateral central areas and the bilateral cerebellum. The voxel-wise approach 
$(\mathrm{p}<0.05, \quad$ FDR corrected, $\mathrm{p}<0.05)$ revealed a significant increase in ${ }^{23} \mathrm{Na}$ signal at ultra short $\mathrm{TE}$ $\left(\mathrm{TE}_{1}=0.2 \mathrm{~ms}\right)$ in the left pre- and post-central regions and a significant decrease in ${ }^{23} \mathrm{Na}$ signal at longer TEs $\left(\mathrm{TE}_{2}=10 \mathrm{~ms}\right.$ and $\mathrm{TE}_{3}=19 \mathrm{~ms}$ ) (Figure 5a). Cluster analyses confirmed that the significantly increased Zscores of the BOLD signal within the left precentral and postcentral areas $\left(Z_{-\mathrm{BOLD}}=4.019, \mathrm{p}=0.0001\right)$ were concordant with a small but significant increase in sodium signal at $\mathrm{TE}_{1}=0.2 \mathrm{~ms} \quad\left(\mathrm{Z}_{-23 \mathrm{Na}} @ \mathrm{TE}_{1}=1.297\right.$, $\mathrm{p}=0.0013$, equivalent signal changes $=+2.8 \%$ ) and a larger decrease in sodium signal at $\mathrm{TE}_{2}=10 \mathrm{~ms}(\mathrm{Z}$ 23Na@ $\mathrm{TE}_{2}=-3.503, \quad \mathrm{p}=0.0012, \quad$ equivalent signal changes $=-16.4 \%)$ and $\mathrm{TE}_{3}=19 \mathrm{~ms}, \quad\left(\mathrm{Z}_{-23 \mathrm{Na}} @ \mathrm{TE}_{3}=-\right.$ $5.806, \mathrm{p}=0.0009$, equivalent signal changes $=-27.2 \%$ ). Similar results were obtained in the BOLD activated region within the right cerebellum $\left(Z{ }_{-{ }_{B O L D}}=1.856\right.$, $\mathrm{p}=0.0001)$ with a significant sodium signal increase at $\mathrm{TE}_{1}\left(\mathrm{Z}-23 \mathrm{Na} @ \mathrm{TE}_{1}=, \quad \mathrm{p}=0.0002\right.$, equivalent signal changes $=+2.3 \%)$ and significant decreases at $\mathrm{TE}_{2}(\mathrm{Z}-$ 23Na@ $\mathrm{TE}_{2}=-3.018, \quad \mathrm{p}=0.0023$, equivalent signal changes $=-10.0 \%)$ and $\mathrm{TE}_{3} \quad\left(\mathrm{Z}_{-23 \mathrm{Na}} @ \mathrm{TE}_{3}=-3.836\right.$, $p=0.0085$, equivalent signal changes $=-17.7 \%$ ) (Figure $5 b)$. The same profiles $\left(Z_{-{ }_{-B L D}}=2.040, p=0.0001\right)$ were observed in the SMA at $\mathrm{TE}_{1}$ (Z23Na@ $\mathrm{TE}_{1}=1.236, \quad \mathrm{p}=0.0085$, equivalent signal changes $=+3.8 \%$ ), at $\mathrm{TE}_{2}$ (for $\mathrm{Z}_{-23 \mathrm{Na}} @ \mathrm{TE}_{2}=-4.377$, $\mathrm{p}=0.0245$, equivalent signal changes $=-28.4 \%$ ) and $\mathrm{TE}_{3}$ (for Z-23Na@ $\mathrm{TE}_{3}=-7.389, \mathrm{p}=0.0085$, equivalent signal changes $=-36.9 \%)($ Supplemental Figure $2 \mathrm{a})$.

\section{${ }^{23} \mathrm{Na}$ signal variations in the BOLD deactivated}

regions

In inhibited regions (negative BOLD contrast) following the right hand movement (i.e. right pre- and post-central regions), we observed significant decrease in ${ }^{23} \mathrm{Na}$ signal at $\mathrm{TE}_{1}=0.2 \mathrm{~ms}$ but significant increase in ${ }^{23} \mathrm{Na}$ signal at longer $\mathrm{TE}\left(\mathrm{TE}_{2}=10 \mathrm{~ms}\right.$ and $\mathrm{TE}_{3}=19 \mathrm{~ms}$ ) (Figures 6a). The cluster analyses confirmed that the significant decreases in Z-scores of the BOLD signal within the right precentral and postcentral areas $\left(Z-{ }_{\text {BOLD }}=-1.895, p=0.0001\right)$ were concordant with negative Z-scores of the sodium signal at $\mathrm{TE}_{1} \quad\left(\mathrm{Z}-23 \mathrm{Na} @ \mathrm{TE}_{1}=-0.864, \quad \mathrm{p}=0.0031\right.$, equivalent signal changes $=-1.5 \%$ ) and to positive $\mathrm{Z}$ scores of sodium signals at $\mathrm{TE}_{2}\left(\mathrm{Z}-\mathrm{-}_{23 \mathrm{Na}} @ \mathrm{TE}_{2}=4.073\right.$, $\mathrm{p}=0.0012$, equivalent signal changes $=+16.7 \%$ ) and $\mathrm{TE}_{3}\left(\mathrm{Z}-23 \mathrm{Na} @ \mathrm{TE}_{3}=3.335, \mathrm{p}=0.0002\right.$, equivalent signal changes $=+15.5 \%$ ). Similar results were obtained in the BOLD deactivated regions (for $\mathrm{Z}_{-\mathrm{BOLD}}=-0.602$, $\mathrm{p}=0.0001$ ) within the left cerebellum (Figure 6b) at $\mathrm{TE}_{1}\left(\mathrm{Z}-23 \mathrm{Na} @ \mathrm{TE}_{1}=-1.288, \mathrm{p}=0.0107\right.$, equivalent signal changes $=-3.4 \%), \quad$ at $\quad \mathrm{TE}_{2} \quad\left(\mathrm{Z}_{-23 \mathrm{Na}} @ \quad \mathrm{TE}_{2}=2.657\right.$, $\mathrm{p}=0.0001$, equivalent signal changes $=+11.3 \%$ ) and $\mathrm{TE}_{3}\left(\mathrm{Z}-23 \mathrm{Na} @ \mathrm{TE}_{3}=3.491, \mathrm{p}=0.0134\right.$, equivalent signal changes $=+16.9 \%)$. The same profiles $\left(Z{ }_{-B O L D}=-1.234\right.$, $\mathrm{p}=0.0001)$ were observed in the precuneus at $\mathrm{TE}_{1}(\mathrm{Z}$ 23Na $@ \mathrm{TE}_{1}=-0.869, \quad \mathrm{p}=0.0085$, equivalent signal changes $=-1.5 \%$ ), at $\mathrm{TE}_{2}$ (for $\mathrm{Z}_{-23 \mathrm{Na}} @ \mathrm{TE}_{2}=2.789$, $\mathrm{p}=0.0040$, equivalent signal changes $=+10.4 \%$ ) and $\mathrm{TE}_{3}$ (for Z-23Na $@ \mathrm{TE}_{3}=2.851, \mathrm{p}=0.0067$, equivalent signal changes $=-15.0 \%$ ) (Supplemental data Figure 2b).

Modeling of the ${ }^{23} \mathrm{Na}$ variations in the different brain environments within activated and deactivated regions relative to $T E$

The present experimental setup did not allow to evaluating the absolute concentrations of intracellular and extra-cellular brain sodium but just to assess different ${ }^{23} \mathrm{Na}$ signal variations weighted by the mobile and the restricted pools of sodium. Keeping in mind this limitation, we tried to relate the levels of sodium in different environments during resting, excitation and inhibition based on the schematic representation of the neuro-glial-vascular ensemble proposed by Chatton and coworkers (Chatton et al., 2016) (Supp Figure 6a), the known variations of CBV (Ciris et al., 2014) and the extent of $\mathrm{Na}$ exchanges following neuronal activation (Dietzel et al., 1982), 
Then, considering the TE dependencies of the different sodium pools, the variations in sodium signals within different brain environments were modeled according to these conditions (Supp Figure 6 $\mathrm{c}, \mathrm{e})$.

From a physiological point of view within the extracellular space, considering that neuronal activation induces a 30\% increase in CBV (Ciris et al., 2014), a basal blood fraction value of $2.3 \%$ (Hales and Clark, 2013) and $[\mathrm{Na}]_{\text {Blood }}$ of $140 \mathrm{mM}$, the increase in CBV corresponds to a TSC increase of $\sim 1 \mathrm{mM}$. The increase related to $[\mathrm{Na}]_{\text {Blood }}$ is paralleled by a $30 \%$ decrease of the extracellular fraction during activation leading to an overall estimated decrease in the extracellular $[\mathrm{Na}]$ concentrations of about $7 \mathrm{mM}$ (Dietzel et al., 1982). In response to these extracellular changes, the mass conservation law may imply a concurrent increase of intracellular sodium concentrations. (Supp Figure 6 b,c)

In contrast, during neuronal inhibition, CBV decrease induces a decrease in TSC $(-1 \mathrm{mM})$. The extracellular decrease of sodium is largely overcompensated by the $\mathrm{Na}^{+}$efflux from the intracellular compartments concordant with the astrocytic and neural dendritic spine shrinkage occurring during inhibition (Goense et al. 2012) (Supp Figure 6, d,e).

\section{Discussion}

We present results of time-resolved dynamic

${ }^{23} \mathrm{Na}$ MRI with a temporal resolution of $30 \mathrm{~s}$, with sufficient signal to noise ratio to observe the consequences of cortical activation or deactivation on variations in human sodium signals coming from different brain environments. By simultaneously probing total sodium signal and signal from the mobile pools of sodium, we determined that activation induced an increase in TSC consistent with a slight increase in cerebral blood volume, and a decrease in sodium signals at later TEs consistent with an influx of $\mathrm{Na}^{+}$into the intracellular space. Interestingly, contralateral deactivation induced a slight decrease in TSC potentially related to decrease in CBV, and an increase in sodium signal from the mobile pools that may reflect efflux of intracellular $\mathrm{Na}^{+}$.

The temporal resolution of $30 \mathrm{~s}$, while quite long, appeared to be sufficient to observe changes in signal contributions of $\mathrm{Na}^{+}$within restricted and mobile brain environments following excitation and inhibition. In fact, it appears that such a temporal resolution is well suited to study astrocytic processes - one important feature of astrocytic $\left[\mathrm{Na}^{+}\right]_{\mathrm{i}}$ transients is their long duration, persisting for tens of seconds in contrast to $\left[\mathrm{Ca}^{2+}\right]_{\mathrm{i}}$ responses which have been reported to last only hundreds of milliseconds (Bennay et al., 2008) (Kirischuk et al., 2007) (Langer and Rose, 2009).

In terms of excitation, stimulation of neuronal fibers have been reported to increase astrocytic $\left[\mathrm{Na}^{+}\right]_{\mathrm{i}}$ by $10-15 \mathrm{mM}$ (Bennay et al., 2008) (Kirischuk et al., 2007) (Langer and Rose, 2009). This phenomenon has been related to the $\mathrm{Na}^{+}$-dependent clearance of glutamate released following neuronal activation, which is performed mainly by astrocytes (Chatton et al., 2016). The $\mathrm{Na}^{+}$influx alters metabolic demand, as it strongly stimulates the $\mathrm{Na}^{+} / \mathrm{K}^{+}$-ATPase and the associated hydrolysis of ATP (Chatton et al., 2016). From a biomechanical point of view, the apparent concentrations of the mobile pools of sodium are strongly related to the extracellular fraction when considering a constant interstitial sodium concentration of 140mM (Jolivet et al., 2015). During excitation, sodium transients are characterized by significant decreases in extracellular sodium and by concurrent increases in intracellular sodium. These phenomena should reflect cellular swelling and recovery, also characterized by a slow time course of seconds (Traynelis and Dingledine, 1989) (Andrew and MacVicar, 1994). This facet of brain activation independent of neurovascular coupling has also been previously explored from the perspective of diffusionfMRI (DfMRI), providing evidence of neural cell 
swelling in various animal models such as aplysia (Abe et al., 2017b) or anesthetized rats (Abe et al., 2017a) and also in the human brain during visual stimulation (Le Bihan et al., 2006) or cognitive tasks (Aso et al., 2013).

Regarding deactivation, previous work has demonstrated that the negative BOLD response seen in fMRI could be interpreted as the result of inhibitory activity (ipsilateral to behavioural movement) with a concomitant decrease in oxygen levels (Schafer et al., 2012) (Klingner et al., 2010) (Goense et al., 2012). Experimental studies have shown a negative correlation between BOLD responses and resting state GABA concentrations (Lauritzen et al., 2012) (Muthukumaraswamy et al., 2009) (Northoff et al., 2007). Structurally, in situ studies reported that longterm depression mediated by GABA may induce dendritic spine shrinkage of up to $50 \%$ in volume but also astrocytic shrinkage of up to 5\% (Hayama et al., 2013). Notably, dynamic ${ }^{23} \mathrm{Na}$ MRI permitted the demonstration of a reverse process to that observed in the excited cortices (contralateral to hand movement), in terms of alterations in sodium levels in the ipsilateral cortices consistent with biophysical processes occurring during inhibition, for the first time in vivo and non-invasively. The haemodynamic dimension relative to the small decrease in $\mathrm{CBV}$ during inhibition was reflected by a subtle but significant decrease in TSC, which may be related to the increased levels of GABA. Indeed GABA has been reported to reduce signalling to astrocytes and the production of vasoactive substances, reducing blood flow and in turn the oxygen level (Sten et al., 2017). In addition, the increase in signal of the mobile sodium pools during inhibition was in line with a major contribution of extracellular fraction increases and concurrent astrocytic and neuronal dendritic spine shrinkage that have been previously described (Hayama et al., 2013).

This study is subject to several limitations.
While possible misregistration at 7T of the ${ }^{1} \mathrm{H}$-EPI and

${ }^{23} \mathrm{Na}$ MRI acquisitions might be due to the differences in spatial resolution and sensitivity to $\mathrm{B}_{0}$ distortion, the spatial normalization and regional approach helped to minimise the impact of such phenomenon. Realignement procedures using for example high resolution EPI-derived $\mathrm{T}_{1}$ maps and surface coregistration have also been proposed and should be considered for future works (Renvall et al., 2016). While the multi-TE approach appears to differentiate between signatures of pools of sodium subject to varying levels of restriction, it does not permit to the univocal assessment of intra- and extra-cellular sodium concentrations, nor to determine the differences in sodium concentrations between neurons, astrocytes and oligodendrocytes which are known to be drastically different (Jolivet et al., 2015). However, the realistic variations of percentages of ${ }^{23} \mathrm{Na}$ signal observed experimentally with the physiological variations of sodium described in vitro and in situ during activation/deactivation may advocate for a large contribution of the extra-cellular pool to the mobile ${ }^{23} \mathrm{Na}$ signal variations. While the volunteer sample size was limited, this is offset partially by the use of a very well-characterized motor task which permitted focused statistical analyses of sodium variations in a limited number of motor areas. Moreover, the temporal resolution of our dynamic ${ }^{23} \mathrm{Na}$ MRI method - on the order of $30 \mathrm{~s}$ - did not allow us to track fast $(<1 \mathrm{~s})$ variations of sodium occurring after neuronal excitation or inhibition, but was well suited to observe slower processes more related to astrocytic involvement. Further efforts are in progress to improve the temporal resolution through a moving sliding window reconstruction approach and better spatial resolution to limit partial volume effect of CSF. We will also work to directly integrate motion correction during the reconstruction procedure rather than performing post-hoc spatial realignment on reconstructed volumes. Nevertheless, this method 
should open new perspectives for characterizing the distribution of ionic homeostatic dysregulation occurring in pathological states such as in the ictal and even interictal periods for patients with partial epilepsy (Ridley et al., 2017a) or as shown recently in transient migraine (Abad et al., 2018).

In conclusion, the present dynamic ${ }^{23} \mathrm{Na} \mathrm{MRI}$ approach opens a novel window for the studying and/or interpretation of mechanisms occurring in the neuro-glial-vascular ensemble pertaining not only to activation but also during inhibition.

\section{Author Contributions}

Conception and Design: JPR, MB; Data acquisition: JPR, MB, MS, LS, SCG, WZ, Data analysis JPR, MB, MS, MB, Drafting or Revising the Article, JPR, MB, BR, WZ, LS, SCG, MG.

\section{Declaration of Interests:}

This work was supported by the Excellence Initiative of Aix-Marseille University - A*MIDEX, a French "Investissements d'Avenir" programme (A*MIDEXEI-13-07-130115-08.38-7T-AMISTART and A*MIDEX-EI-17-29-170228-09.43-Imetionic-7), Aix-Marseille Université, AP-HM and CNRS (Centre National de la Recherche Scientifique), and ANR grant 'NEUROintraSOD-7T' (ANR-15-CE19-001901).

It was performed on the platform 7T-AMI, a French "Investissements d'Avenir" programme (grant ANR11-EQPX-0001), by a Laboratory member of the France Life Imaging network (grant ANR-11-INBS0006).

The research leading to these results received funding from the People Programme (Marie Curie Actions) of the European Union's Seventh Framework Programme (FP7/2007-2013) under REA grant agreement (PCOFUND-GA-2013-609102), through the PRESTIGE programme coordinated by Campus France.

\section{References}

Abad, N., Rosenberg, J.T., Hike, D.C., Harrington, M.G., Grant, S.C., 2018. Dynamic Sodium Imaging at Ultra-High Field Reveals Progression in a Preclinical Migraine Model.

Pain. https://doi.org/10.1097/j.pain.0000000000001307

Abe, Y., Tsurugizawa, T., Le Bihan, D., 2017a. Water diffusion closely reveals neural activity status in rat brain loci affected by anesthesia. PLoS Biol. 15, e2001494.

https://doi.org/10.1371/journal.pbio.2001494

Abe, Y., Van Nguyen, K., Tsurugizawa, T., Ciobanu, L., Le Bihan, D., 2017b. Modulation of water diffusion by activation-induced neural cell swelling in Aplysia Californica. Sci. Rep. 7, 6178. https://doi.org/10.1038/s41598-017-05586-5

Andrew, R.D., MacVicar, B.A., 1994. Imaging cell volume changes and neuronal excitation in the hippocampal slice. Neuroscience 62, 371-383.

Aso, T., Urayama, S.-I., Fukuyama, H., Le Bihan, D., 2013. Comparison of diffusion-weighted fMRI and BOLD fMRI responses in a verbal working memory task. NeuroImage 67, 25-32. https://doi.org/10.1016/j.neuroimage.2012.11.005

Bennay, M., Langer, J., Meier, S.D., Kafitz, K.W., Rose, C.R., 2008. Sodium signals in cerebellar Purkinje neurons and Bergmann glial cells evoked by glutamatergic synaptic transmission. Glia 56, 11381149. https://doi.org/10.1002/glia.20685

Chatton, J.-Y., Magistretti, P.J., Barros, L.F., 2016. Sodium signaling and astrocyte energy metabolism. Glia 64, 1667-1676. https://doi.org/10.1002/glia.22971

Ciris, P.A., Qiu, M., Constable, R.T., 2014. Noninvasive quantification of absolute cerebral blood volume during functional activation applicable to the whole human brain. Magn. Reson. Med. 71, 580-590. https://doi.org/10.1002/mrm.24694

Dietzel, I., Heinemann, U., Hofmeier, G., Lux, H.D., 
1982. Stimulus-induced changes in extracellular $\mathrm{Na}+$ and $\mathrm{Cl}$ - concentration in relation to changes in the size of the extracellular space. Exp. Brain Res. 46, 73-84. Fessler, J.A., 2007. On NUFFT-based gridding for non-Cartesian MRI. J. Magn. Reson. San Diego Calif $1997188,191-195$.

Goense, J., Merkle, H., Logothetis, N.K., 2012. Highresolution fMRI reveals laminar differences in neurovascular coupling between positive and negative BOLD responses. Neuron 76, 629-639. https://doi.org/10.1016/j.neuron.2012.09.019

Hales, P.W., Clark, C.A., 2013. Combined arterial spin labeling and diffusion-weighted imaging for noninvasive estimation of capillary volume fraction and permeability-surface product in the human brain. J. Cereb. Blood Flow Metab. Off. J. Int. Soc. Cereb. Blood Flow Metab. 33, 67-75. https://doi.org/10.1038/jcbfm.2012.125

Hall, C.N., Reynell, C., Gesslein, B., Hamilton, N.B., Mishra, A., Sutherland, B.A., O’Farrell, F.M., Buchan, A.M., Lauritzen, M., Attwell, D., 2014. Capillary pericytes regulate cerebral blood flow in health and disease. Nature 508, 55-60. https://doi.org/10.1038/nature13165

Hayama, T., Noguchi, J., Watanabe, S., Takahashi, N., Hayashi-Takagi, A., Ellis-Davies, G.C.R., Matsuzaki, M., Kasai, H., 2013. GABA promotes the competitive selection of dendritic spines by controlling local Ca2+ signaling. Nat. Neurosci. 16, 1409-1416. https://doi.org/10.1038/nn.3496

He, Y., Wang, M., Chen, X., Pohmann, R., Polimeni, J.R., Scheffler, K., Rosen, B.R., Kleinfeld, D., Yu, X., 2018. Ultra-Slow Single-Vessel BOLD and CBVBased fMRI Spatiotemporal Dynamics and Their Correlation with Neuronal Intracellular Calcium Signals.

Neuron.

https://doi.org/10.1016/j.neuron.2018.01.025

Hussain, M.S., Stobbe, R.W., Bhagat, Y.A., Emery, D., Butcher, K.S., Manawadu, D., Rizvi, N., Maheshwari, P., Scozzafava, J., Shuaib, A., Beaulieu,
C., 2009. Sodium imaging intensity increases with time after human ischemic stroke. Ann. Neurol. 66, 55-62. https://doi.org/10.1002/ana.21648

Inglese, M., Madelin, G., Oesingmann, N., Babb, J.S., Wu, W., Stoeckel, B., Herbert, J., Johnson, G., 2010. Brain tissue sodium concentration in multiple sclerosis: a sodium imaging study at 3 tesla. Brain J. Neurol.

133 , $847-857$. https://doi.org/10.1093/brain/awp334

Jolivet, R., Coggan, J.S., Allaman, I., Magistretti, P.J., 2015. Multi-timescale modeling of activity-dependent metabolic coupling in the neuron-glia-vasculature ensemble. PLoS Comput. Biol. 11, e1004036. https://doi.org/10.1371/journal.pcbi.1004036

Kirischuk, S., Kettenmann, H., Verkhratsky, A., 2007. Membrane currents and cytoplasmic sodium transients generated by glutamate transport in Bergmann glial cells. Pflugers Arch. 454, 245-252. https://doi.org/10.1007/s00424-007-0207-5

Klingner, C.M., Hasler, C., Brodoehl, S., Witte, O.W., 2010. Dependence of the negative BOLD response on somatosensory stimulus intensity. NeuroImage 53, 189-195.

https://doi.org/10.1016/j.neuroimage.2010.05.087

Langer, J., Rose, C.R., 2009. Synaptically induced sodium signals in hippocampal astrocytes in situ. J. Physiol. 587 , 5859-5877. https://doi.org/10.1113/jphysiol.2009.182279

Lauritzen, M., Mathiesen, C., Schaefer, K., Thomsen, K.J., 2012. Neuronal inhibition and excitation, and the dichotomic control of brain hemodynamic and oxygen responses. NeuroImage 62, 1040-1050. https://doi.org/10.1016/j.neuroimage.2012.01.040

Le Bihan, D., Urayama, S., Aso, T., Hanakawa, T., Fukuyama, H., 2006. Direct and fast detection of neuronal activation in the human brain with diffusion MRI. Proc. Natl. Acad. Sci. U. S. A. 103, 8263-8268. https://doi.org/10.1073/pnas.0600644103

Lundengard, K., Cedersund, G., Sten, S., Leong, F., Smedberg, A., Elinder, F., Engstrom, M., 2016. 
Mechanistic Mathematical Modeling Tests Hypotheses of the Neurovascular Coupling in fMRI. PLoS Comput. Biol. 12, e1004971. https://doi.org/10.1371/journal.pcbi.1004971

Maarouf, A., Audoin, B., Pariollaud, F., Gherib, S., Rico, A., Soulier, E., Confort-Gouny, S., Guye, M., Schad, L., Pelletier, J., Ranjeva, J.-P., Zaaraoui, W., 2017. Increased total sodium concentration in gray matter better explains cognition than atrophy in MS. Neurology 88 ,

289-295. https://doi.org/10.1212/WNL.0000000000003511

Madelin, G., Lee, J.-S., Regatte, R.R., Jerschow, A., 2014. Sodium MRI: methods and applications. Prog. Nucl. Magn. Reson. Spectrosc. 79, 14-47. https://doi.org/10.1016/j.pnmrs.2014.02.001

Mellon, E.A., Pilkinton, D.T., Clark, C.M., Elliott, M.A., Witschey, W.R. 2nd, Borthakur, A., Reddy, R., 2009. Sodium MR imaging detection of mild Alzheimer disease: preliminary study. AJNR Am. J. Neuroradiol. 30 978-984. https://doi.org/10.3174/ajnr.A1495

Muthukumaraswamy, S.D., Edden, R.A.E., Jones, D.K., Swettenham, J.B., Singh, K.D., 2009. Resting GABA concentration predicts peak gamma frequency and fMRI amplitude in response to visual stimulation in humans. Proc. Natl. Acad. Sci. U. S. A. 106, 83568361. https://doi.org/10.1073/pnas.0900728106

Nagel, A.M., Laun, F.B., Weber, M.-A., Matthies, C., Semmler, W., Schad, L.R., 2009. Sodium MRI using a density-adapted 3D radial acquisition technique. Magn. Reson. Med. 62, 1565-1573. https://doi.org/10.1002/mrm.22157

Northoff, G., Walter, M., Schulte, R.F., Beck, J., Dydak, U., Henning, A., Boeker, H., Grimm, S., Boesiger, P., 2007. GABA concentrations in the human anterior cingulate cortex predict negative BOLD responses in fMRI. Nat. Neurosci. 10, 15151517. https://doi.org/10.1038/nn2001

Ogawa, S., Lee, T.M., Kay, A.R., Tank, D.W., 1990. Brain magnetic resonance imaging with contrast dependent on blood oxygenation. Proc. Natl. Acad. Sci. U. S. A. 87, 9868-9872.

Reetz, K., Romanzetti, S., Dogan, I., Sass, C., Werner, C.J., Schiefer, J., Schulz, J.B., Shah, N.J., 2012. Increased brain tissue sodium concentration in Huntington's Disease - a sodium imaging study at $4 \mathrm{~T}$. NeuroImage 63 ,

517-524. https://doi.org/10.1016/j.neuroimage.2012.07.009

Renvall, V., Witzel, T., Wald, L.L., Polimeni, J.R., 2016. Automatic cortical surface reconstruction of high-resolution T1 echo planar imaging data. NeuroImage 134, 338-354. https://doi.org/10.1016/j.neuroimage.2016.04.004

Ridley, B., Marchi, A., Wirsich, J., Soulier, E., Confort-Gouny, S., Schad, L., Bartolomei, F., Ranjeva, J.-P., Guye, M., Zaaraoui, W., 2017a. Brain sodium MRI in human epilepsy: Disturbances of ionic homeostasis reflect the organization of pathological regions. NeuroImage 157, 173-183. https://doi.org/10.1016/j.neuroimage.2017.06.011

Ridley, B., Nagel, A.M., Bydder, M., Maarouf, A., Stellmann, Jan-Patrick, Gherib, S., Verneuil, Jeremy, Viout, P., Guye, M., Ranjeva, J.P., Zaaraoui, W., 2018. Distribution of brain sodium long and short relaxation times and concentrations: a multi-echo ultra-high field 23Na MRI study. Sci. Rep.

Ridley, B., Wirsich, J., Bettus, G., Rodionov, R., Murta, T., Chaudhary, U., Carmichael, D., Thornton, R., Vulliemoz, S., McEvoy, A., Wendling, F., Bartolomei, F., Ranjeva, J.-P., Lemieux, L., Guye, M., 2017b. Simultaneous Intracranial EEG-fMRI Shows Inter-Modality Correlation in Time-Resolved Connectivity Within Normal Areas but Not Within Epileptic Regions. Brain Topogr. 30, 639-655. https://doi.org/10.1007/s10548-017-0551-5

Rooney, W.D., Springer, C.S.J., 1991. The molecular environment of intracellular sodium: $23 \mathrm{Na}$ NMR relaxation. NMR Biomed. 4, 227-245.

Rose, C.R., Chatton, J.-Y., 2016. Astrocyte sodium signaling and neuro-metabolic coupling in the brain. 
https://doi.org/10.1016/j.neuroscience.2015.03.002

Schafer, K., Blankenburg, F., Kupers, R., Gruner, J.M., Law, I., Lauritzen, M., Larsson, H.B.W., 2012. Negative BOLD signal changes in ipsilateral primary somatosensory cortex are associated with perfusion decreases and behavioral evidence for functional inhibition. NeuroImage 59, 3119-3127. https://doi.org/10.1016/j.neuroimage.2011.11.085

Shine, J.M., Bissett, P.G., Bell, P.T., Koyejo, O., Balsters, J.H., Gorgolewski, K.J., Moodie, C.A., Poldrack, R.A., 2016. The Dynamics of Functional Brain Networks: Integrated Network States during Cognitive Task Performance. Neuron 92, 544-554. https://doi.org/10.1016/j.neuron.2016.09.018

Sten, S., Lundengard, K., Witt, S.T., Cedersund, G., Elinder, F., Engstrom, M., 2017. Neural inhibition can explain negative BOLD responses: A mechanistic modelling and fMRI study. NeuroImage 158, 219231.

https://doi.org/10.1016/j.neuroimage.2017.07.002

Stobbe, R.W., Beaulieu, C., 2016. Residual quadrupole interaction in brain and its effect on quantitative sodium imaging. NMR Biomed. 29, 119 128. https://doi.org/10.1002/nbm.3376

T Vu, A., Jamison, K., Glasser, M.F., Smith, S.M., Coalson, T., Moeller, S., Auerbach, E.J., Ugurbil, K., Yacoub, E., 2017. Tradeoffs in pushing the spatial resolution of fMRI for the 7T Human Connectome Project. NeuroImage 154, 23-32.
Thulborn, K.R., 2016. Quantitative sodium MR imaging: A review of its evolving role in medicine. NeuroImage.

https://doi.org/10.1016/j.neuroimage.2016.11.056

Thulborn, K.R., Lu, A., Atkinson, I.C., Damen, F., Villano, J.L., 2009. Quantitative sodium MR imaging and sodium bioscales for the management of brain tumors. Neuroimaging Clin. N. Am. 19, 615-624. https://doi.org/10.1016/j.nic.2009.09.001

Traynelis, S.F., Dingledine, R., 1989. Role of extracellular space in hyperosmotic suppression of potassium-induced electrographic seizures. J. Neurophysiol. $\quad 61, \quad 927-938$. https://doi.org/10.1152/jn.1989.61.5.927

Xue, H., Inati, S., Sorensen, T.S., Kellman, P., Hansen, M.S., 2015. Distributed MRI reconstruction using Gadgetron-based cloud computing. Magn. Reson. Med. 73, 1015-1025. https://doi.org/10.1002/mrm.25213

Zaaraoui, W., Konstandin, S., Audoin, B., Nagel, A.M., Rico, A., Malikova, I., Soulier, E., Viout, P., Confort-Gouny, S., Cozzone, P.J., Pelletier, J., Schad, L.R., Ranjeva, J.-P., 2012. Distribution of brain sodium accumulation correlates with disability in multiple sclerosis: a cross-sectional $23 \mathrm{Na} \mathrm{MR}$ imaging study. Radiology 264, 859-867. https://doi.org/10.1148/radiol.12112680 


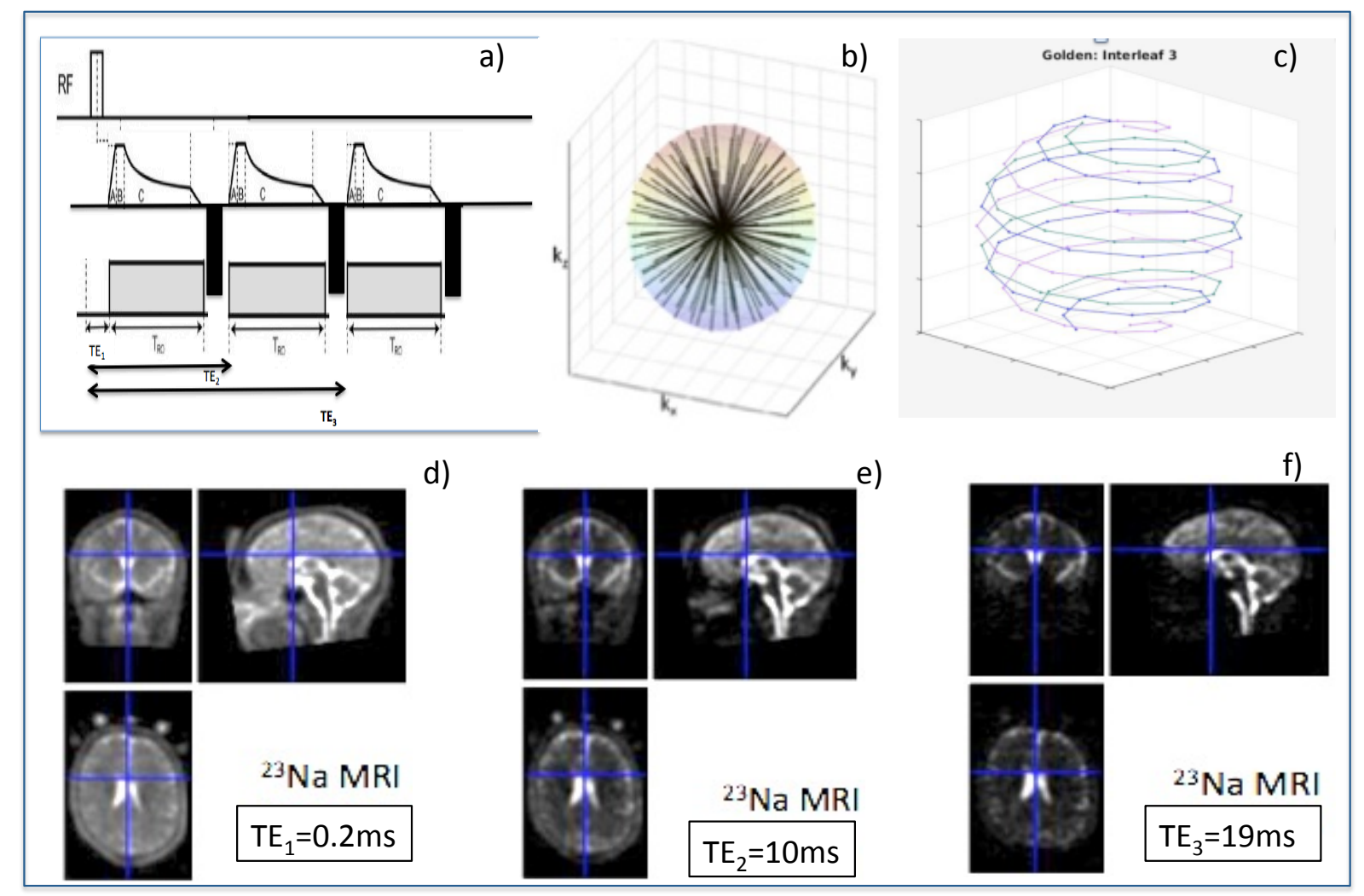

Figure 1: Principle of the dynamic ${ }^{23} \mathrm{Na}$ MRI sequence and examples of reconstructed images

a) Chronogram of the triple-TE density adapted radial ${ }^{23} \mathrm{Na}$ MRI sequence. b) Representation of the full-k space coverage (10080 projections) for one echo. c) Example of azimuths of 3 interleaved series of 240 stacks homogenously covering the full extent of $\mathrm{k}$-space and subsequently weighted by a factor of 100 to introduce the temporal weighting. Bottom row d,e,f) Examples of ${ }^{23} \mathrm{Na}$ MRI volumes obtained with the three different TEs using dynamic reconstruction. 


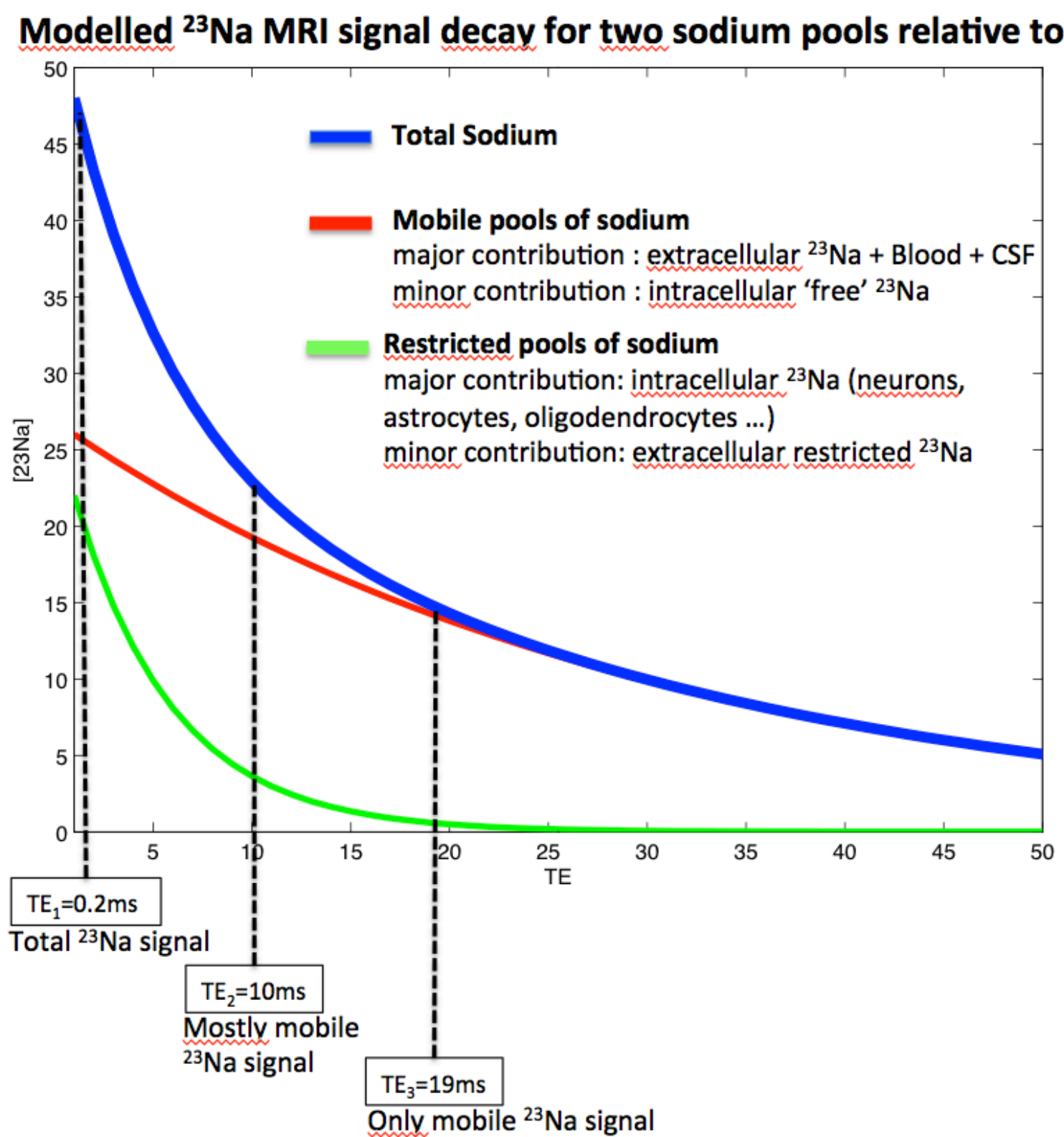

Figure 2: Modeled ${ }^{23} \mathrm{Na}$ MR signal decays for total, mobile and restricted pools of sodium in gray matter Modeled curves generated according to measurements obtained on healthy volunteers using 24 TEs (range: $0.2 \mathrm{~ms}-100 \mathrm{~ms})^{21}$ considering a bi-exponential decay of the total sodium signal leading to the following parameters: $[\mathrm{TSC}]=47 \mathrm{mM},[\mathrm{Na}]_{\text {mobile }}=26 \mathrm{mM},[\mathrm{Na}]_{\text {restricted }}=21 \mathrm{mM}, \mathrm{T}_{2} *\left(\mathrm{Na}\right.$ mobile $\left._{\text {e }}\right)=31 \mathrm{~ms}, \mathrm{~T}_{2} *(\mathrm{Na}$ restricted $)=5 \mathrm{~ms}$. 


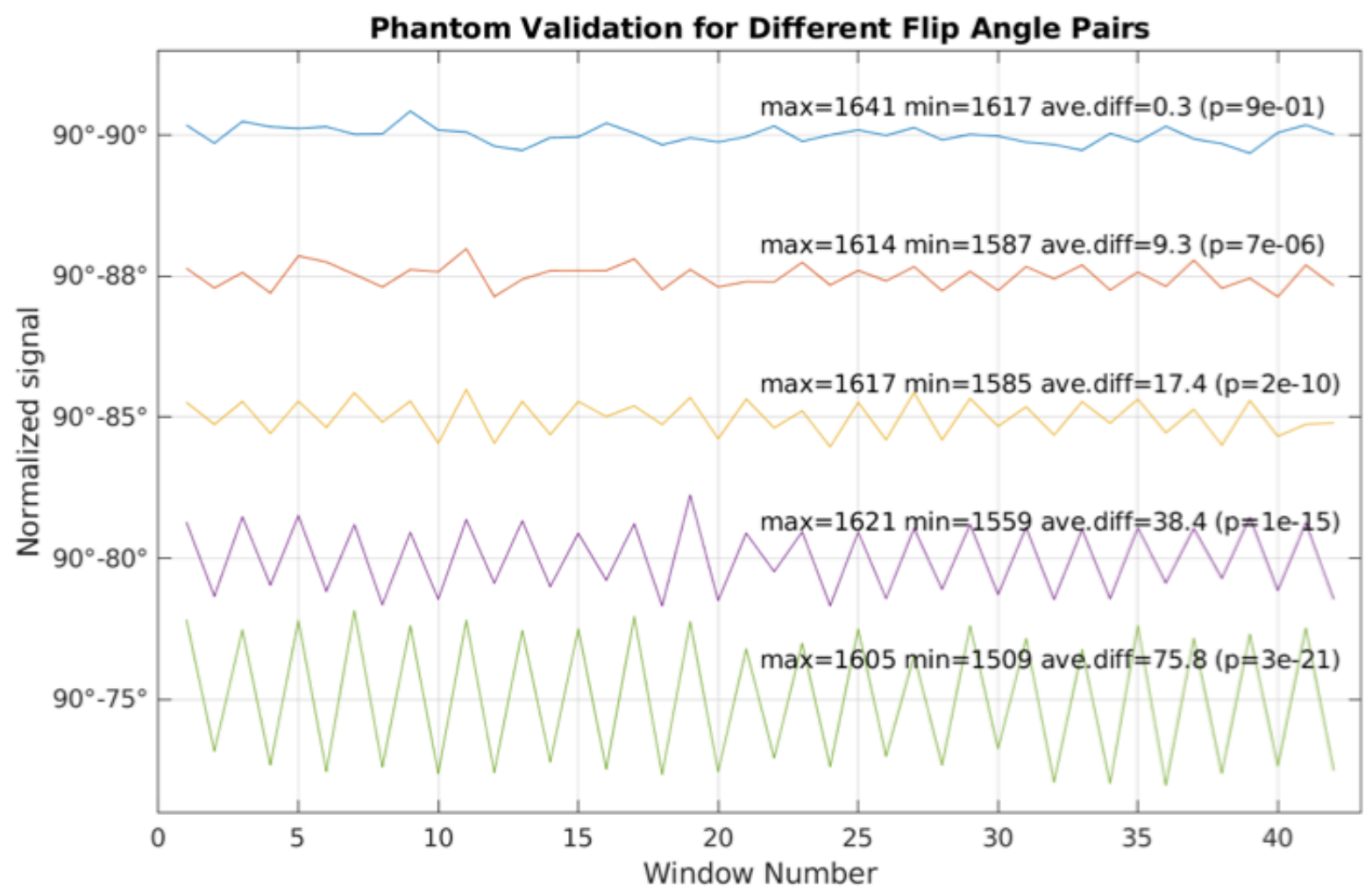

Figure 3: Demonstration of the temporal information extracted using the dynamic ${ }^{23} \mathrm{Na}$ MRI acquisition

${ }^{23} \mathrm{Na}$ signal variations obtained on a phantom at $\mathrm{TE}_{1}=0.2 \mathrm{~ms}$ and reconstruction on a phantom. Every $30 \mathrm{~s}$, acquisition parameters (flip angles) varied leading to a significant ${ }^{23} \mathrm{Na}$ MR signal change that could be easily be observed. 


\section{BOLD signal variations during right hand motion}

a) BOLD signal increases

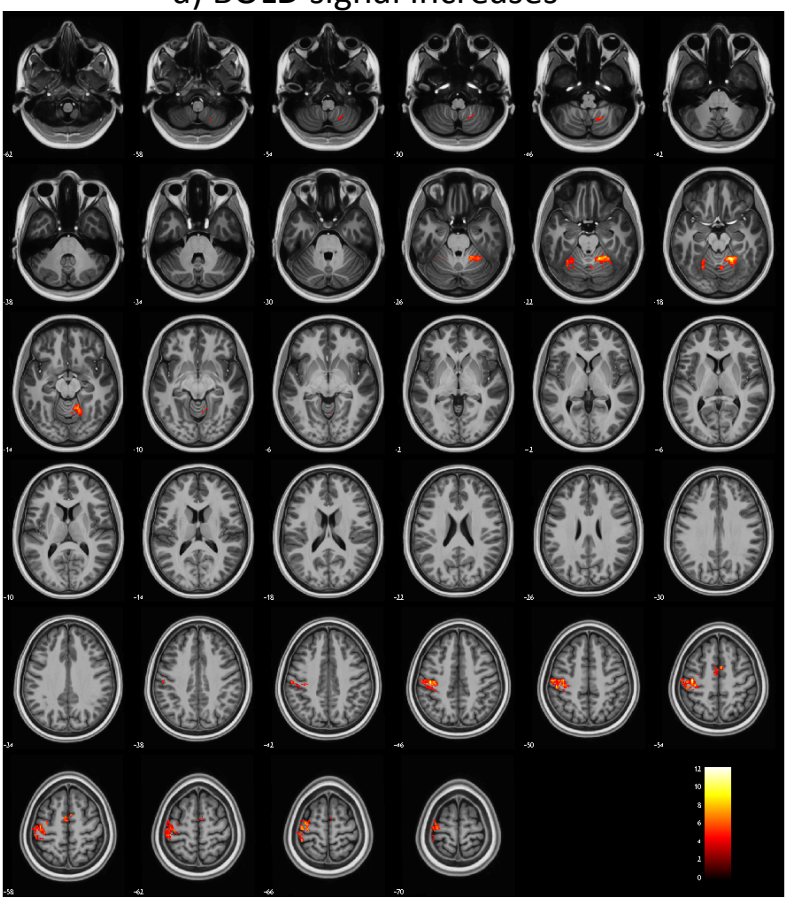

One sample t-test $\left(\mathrm{p}<0.005, \mathrm{k}=5, \mathrm{FDR}_{\text {corr }} \mathrm{p}<0.05\right)$ b) BOLD signal decreases

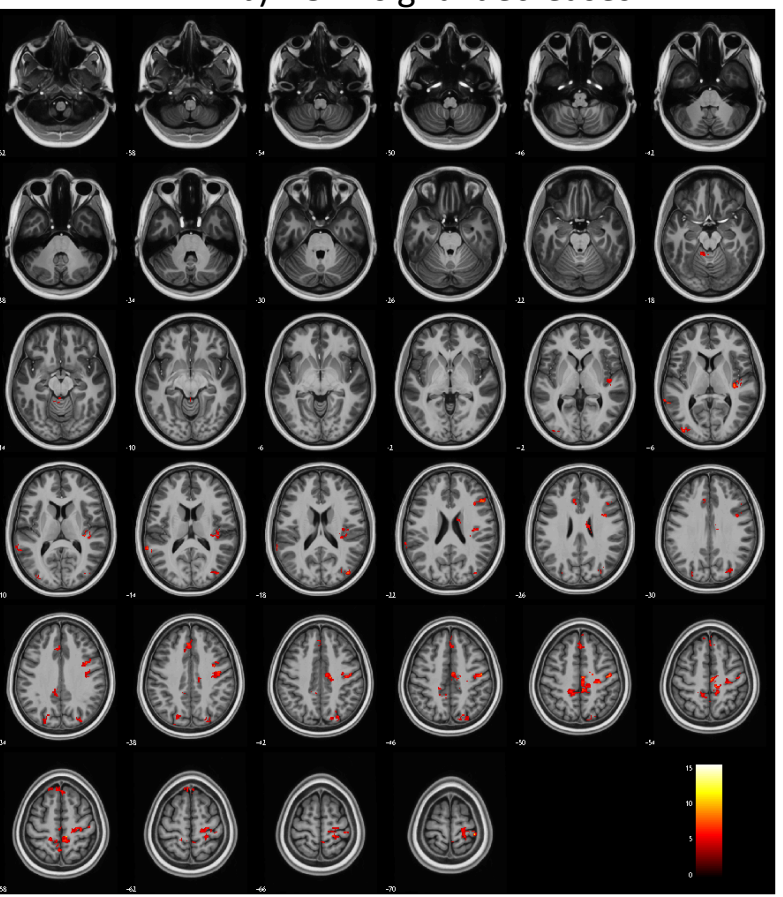

Figure 4: Positive BOLD contrast (top) and negative BOLD contrast (bottom) following right hand task Group positive (a) and negative (b) BOLD contrast patterns during the right hand task in the fourteen healthy volunteers. (One sample $\mathrm{t}$-test, $\mathrm{p}<0.005, \mathrm{k}=5$ FDR corrected $\mathrm{p}<0.05$ ). 


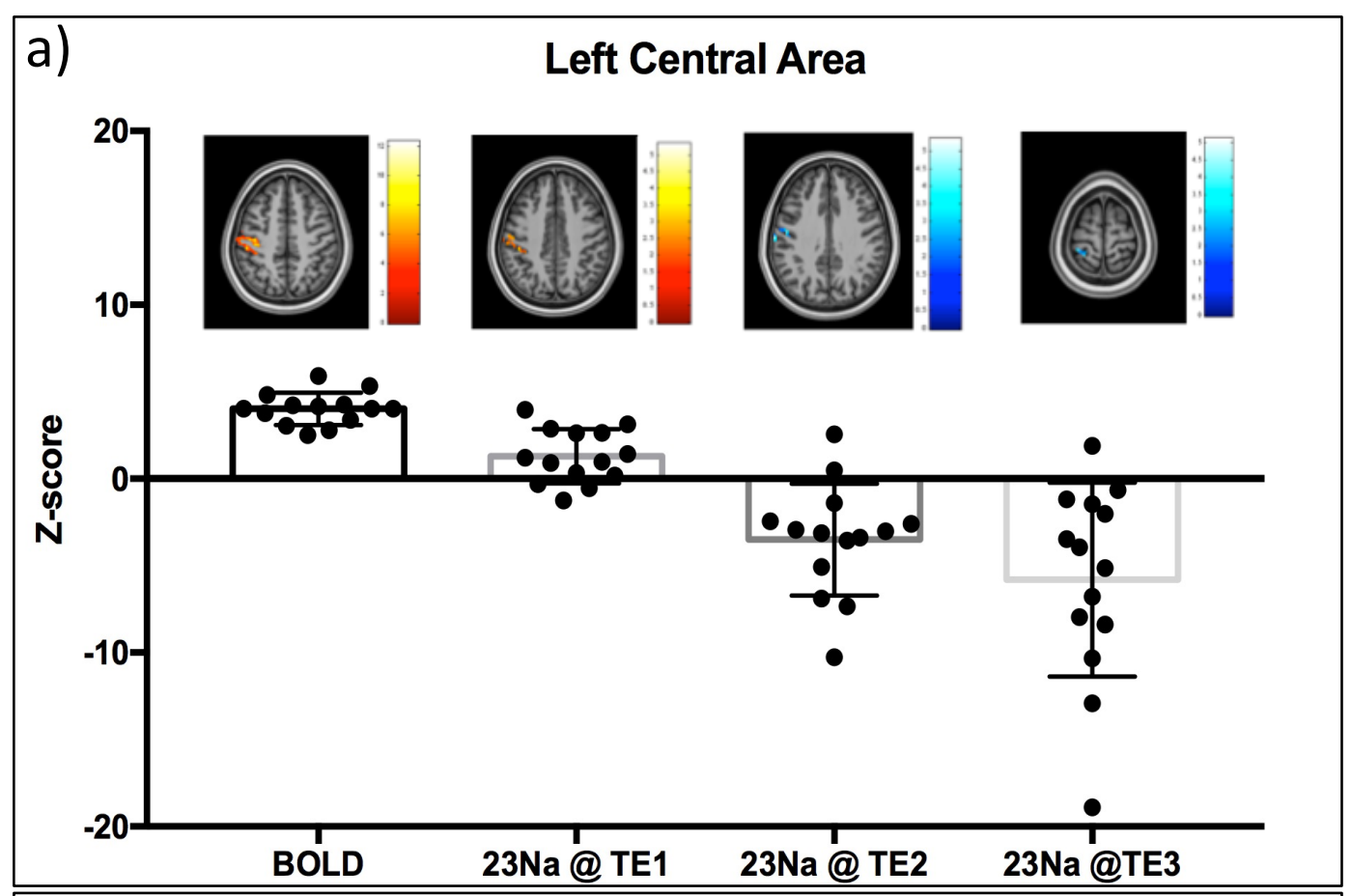

b)

Right Cerebellum

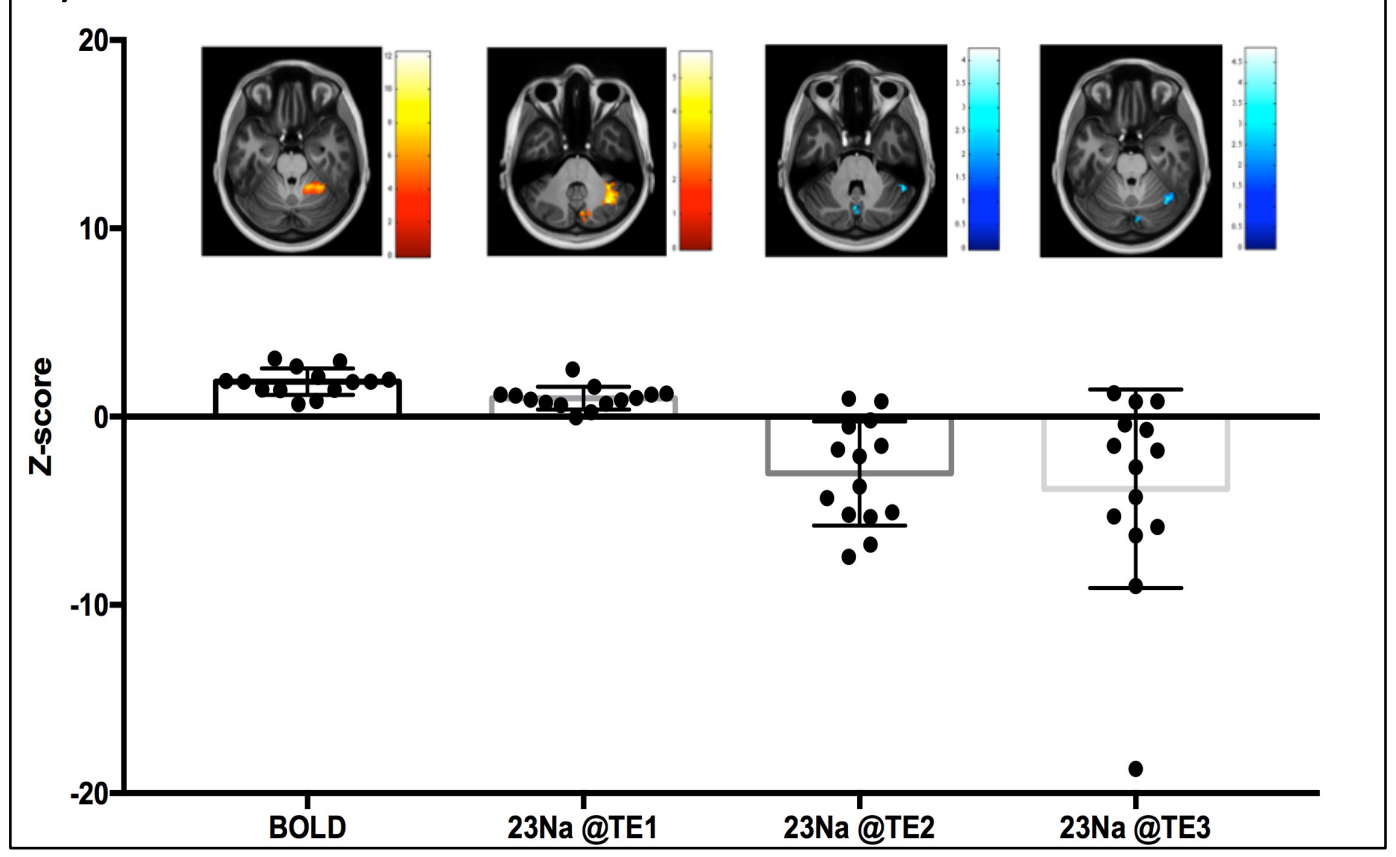

Figure 5: Cluster analyses of signal variations in Activated areas during the right hand movement.

The positive BOLD contrast observed in the left pre-/post- central areas (a) and the right cerebellum (b) corresponds to ${ }^{23} \mathrm{Na}$ signal increase at $\mathrm{TE}_{1}$ and ${ }^{23} \mathrm{Na}$ signal decreases at $\mathrm{TE}_{2}$ and $\mathrm{TE}_{3}$. 

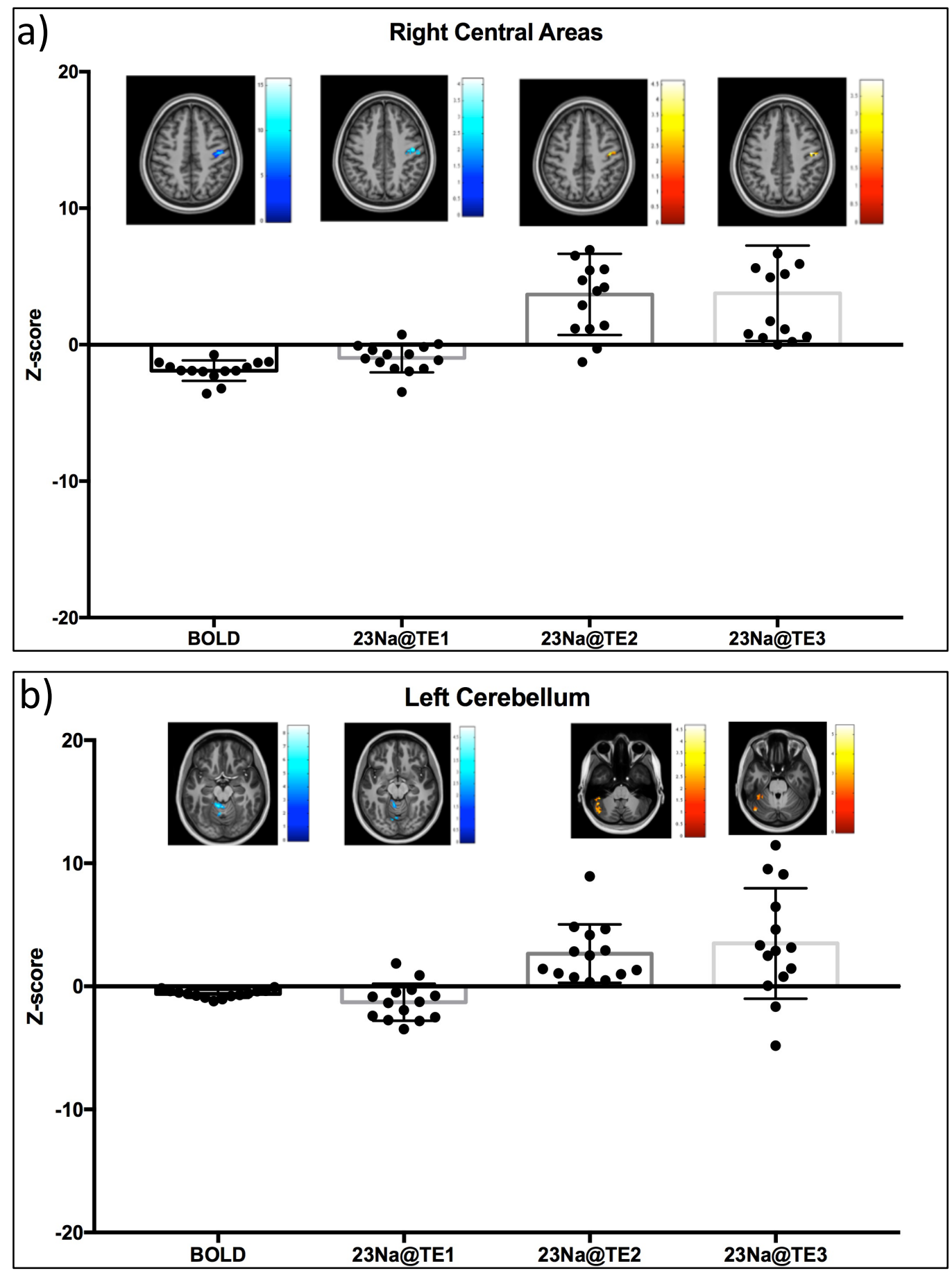

Figure 6: Cluster analyses of signal variations in inhibited areas during the right hand movement.

The negative BOLD contrast observed in the right pre-/post- central areas (a) and the left cerebellum (b) corresponds to ${ }^{23} \mathrm{Na}$ signal decrease at $\mathrm{TE}_{1}$ and ${ }^{23} \mathrm{Na}$ signal increases at $\mathrm{TE}_{2}$ and $\mathrm{TE}_{3}$. 
a)

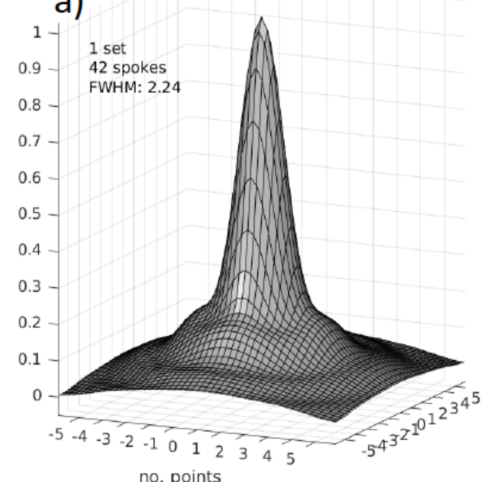

b)

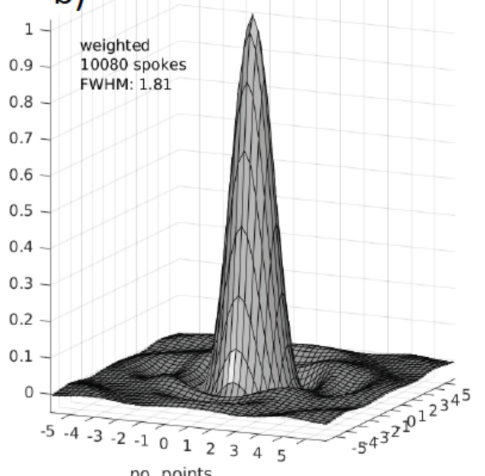

c)

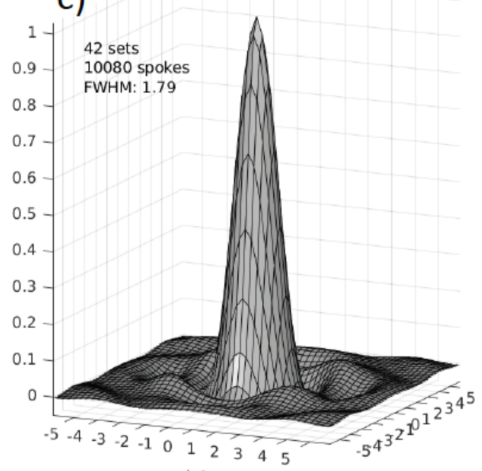

Supplemental data Figure 1: Point spread function of the different ${ }^{23} \mathrm{Na}$ MRI acquisitions

Point spread functions (PSF) of a) one set of data (240 spokes acquired using golden angle approach, temporal resolution 30s) with aPSF FWHM of 2.24 points corresponding to $7.84 \mathrm{~mm}$, b) the weighted ${ }^{23 \mathrm{Na}} \mathrm{MRI}$ acquisition used for ${ }^{23} \mathrm{Na}$ fMRI (weighted 10080 spokes, temporal resolution $30 \mathrm{~s}$ ) with a PSFFHн of 1.81 points corresponding to $6.34 \mathrm{~mm}$ and c) the whole k-space sampling (10080 spokes, temporal resolution 20min10s) with a PSFFWHM of 1.79 points corresponding to $6.27 \mathrm{~mm}$. 

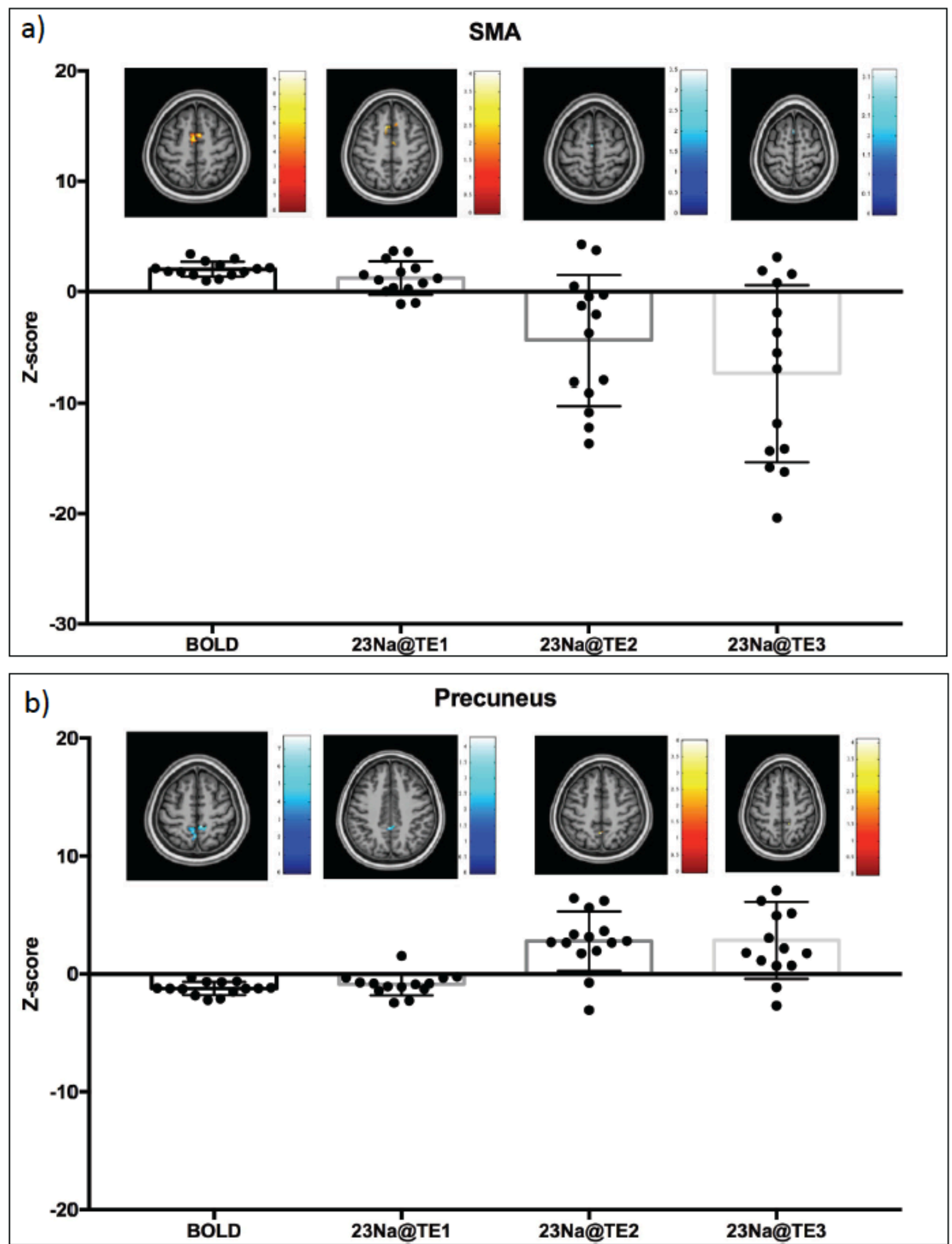

Supplemental data Figure 2

Signal variations during the right hand motor task in a) the supplementary motor area, and b) the precuneus. 


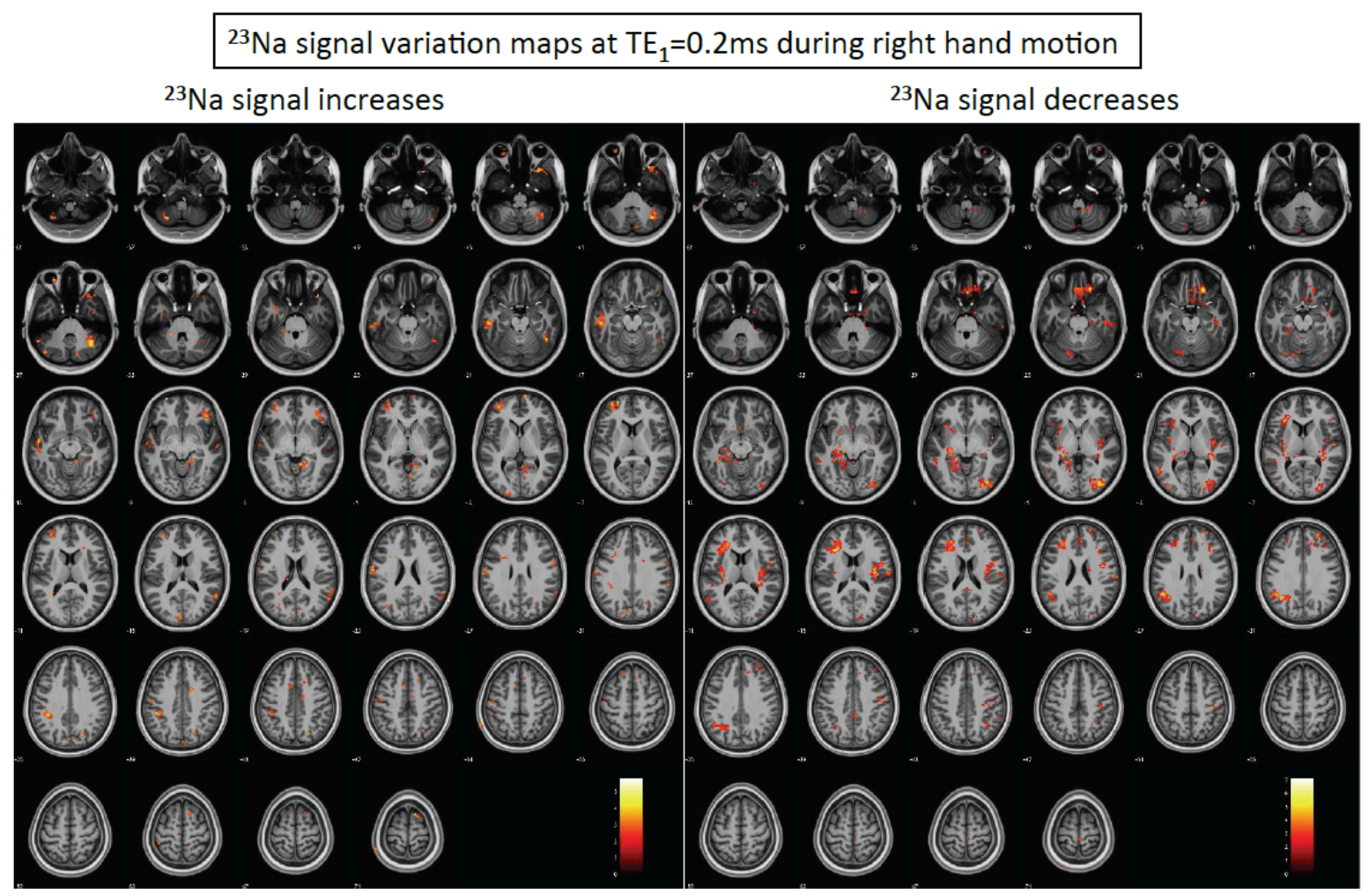

One sample t-test $\left(p<0.02, k=10, F_{\text {corr }} p<0.05\right)$

Supplemental data Figure 3:

${ }^{23} \mathrm{Na}$ signal variation maps at $\mathrm{TE}_{1}=0.2 \mathrm{~ms}$ observed during the right hand motor task. 


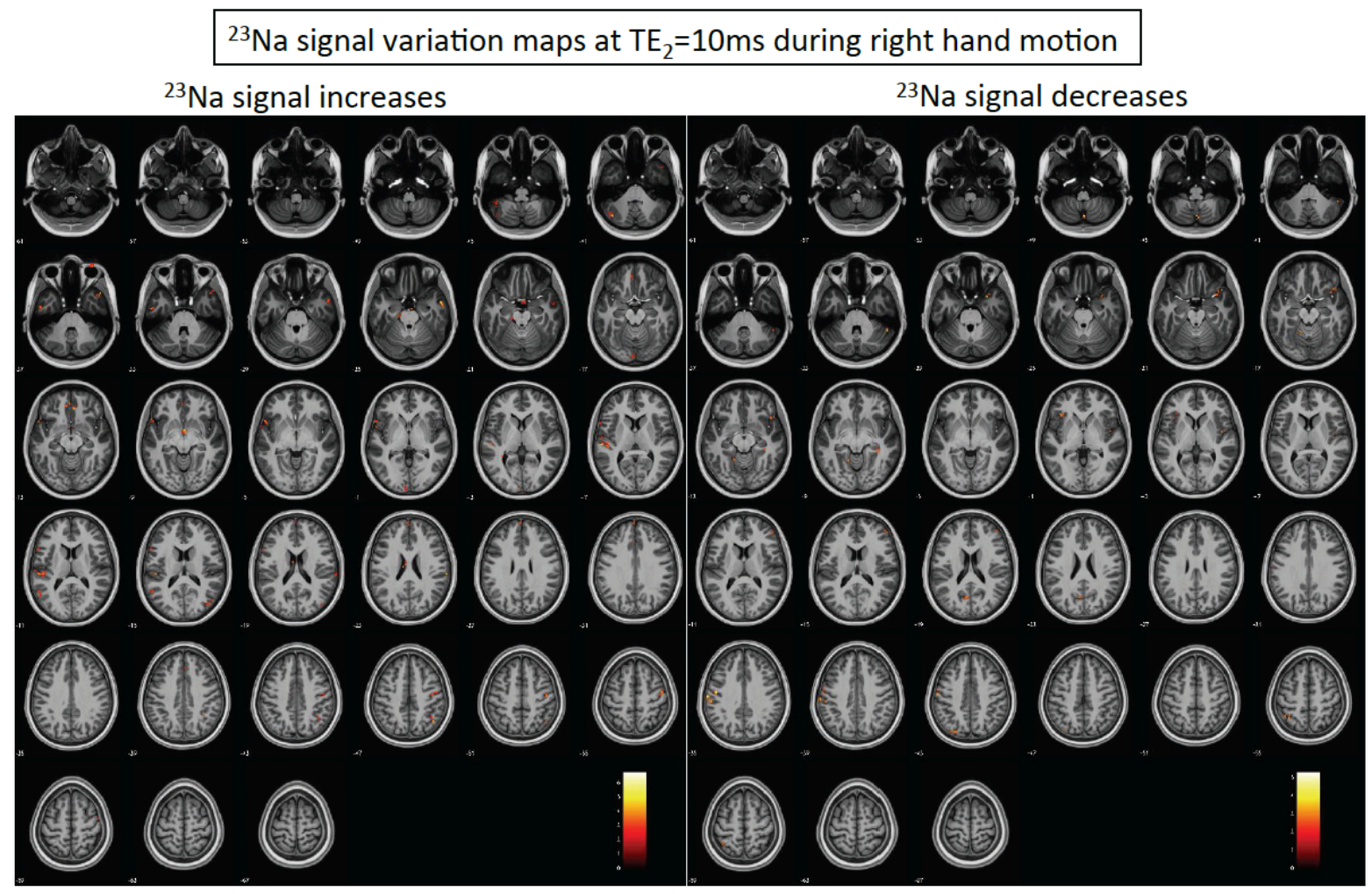

One sample t-test $\left(p<0.02, k=10, F_{\text {corr }} p<0.05\right)$

Supplemental data Figure 4: ${ }^{23} \mathrm{Na}$ signal variation maps at $\mathrm{TE}_{2}=10 \mathrm{~ms}$ observed during the right hand motor task. 


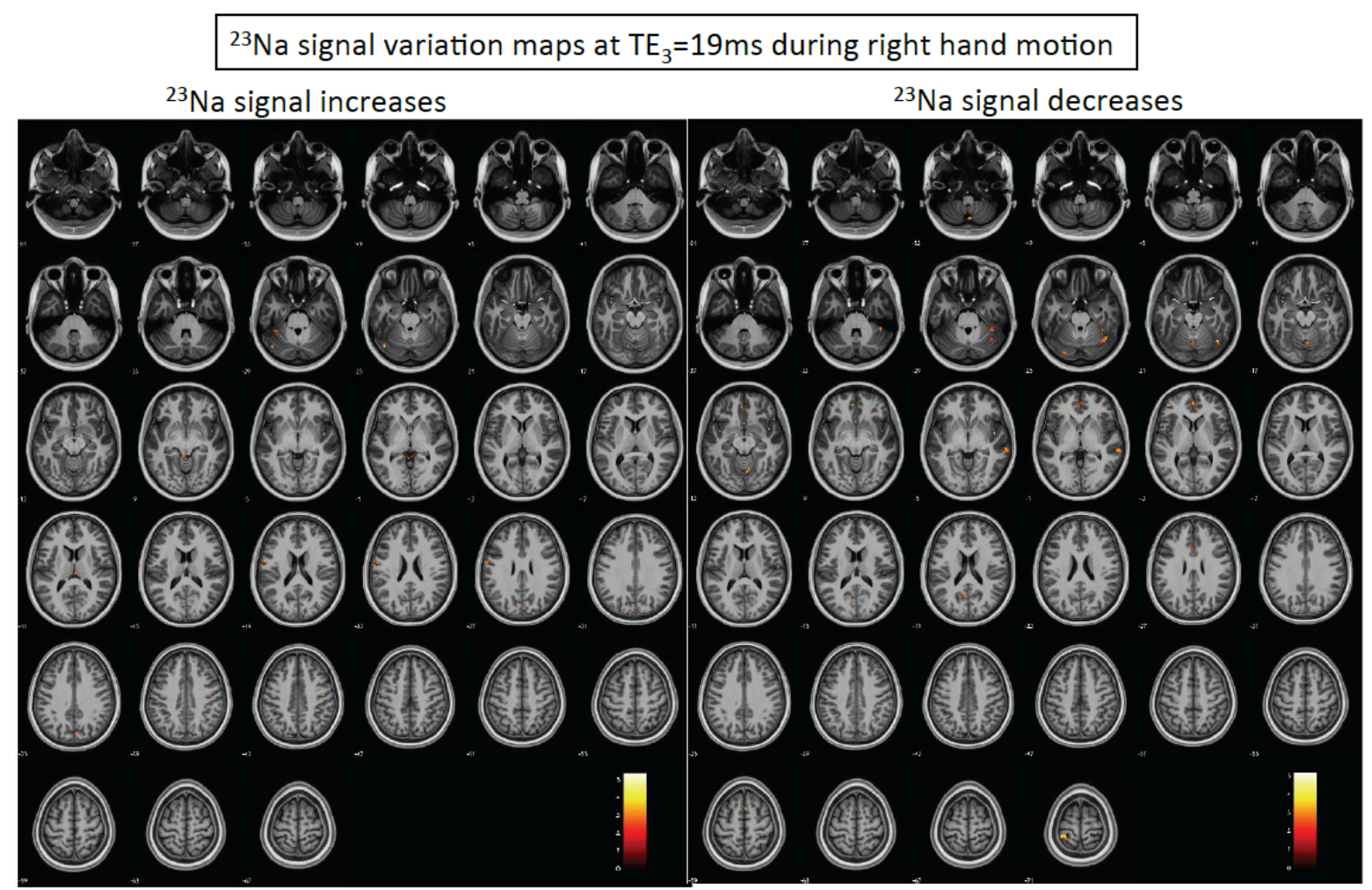

One sample t-test $\left(p<0.02, k=10, F_{\text {corr }} p<0.05\right)$

Supplemental data Figure 5 :

${ }^{23} \mathrm{Na}$ signal variation maps at $\mathrm{TE}_{3}=19 \mathrm{~ms}$ observed during the right hand motor task. 


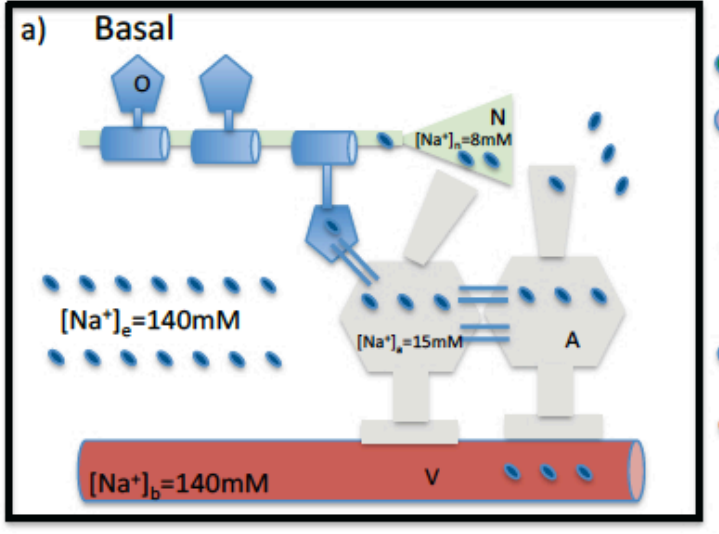

\author{
Glutamate \\ GABA \\ $\mathrm{Na}^{+}$ \\ $\downarrow$ Vasoactive species \\ acting on pericytes \\ Lactate \\ Glucose
}

$\mathrm{N}$ : Neurons, O: Oligodendrocytes

A: Astrocytes, V: Vessels
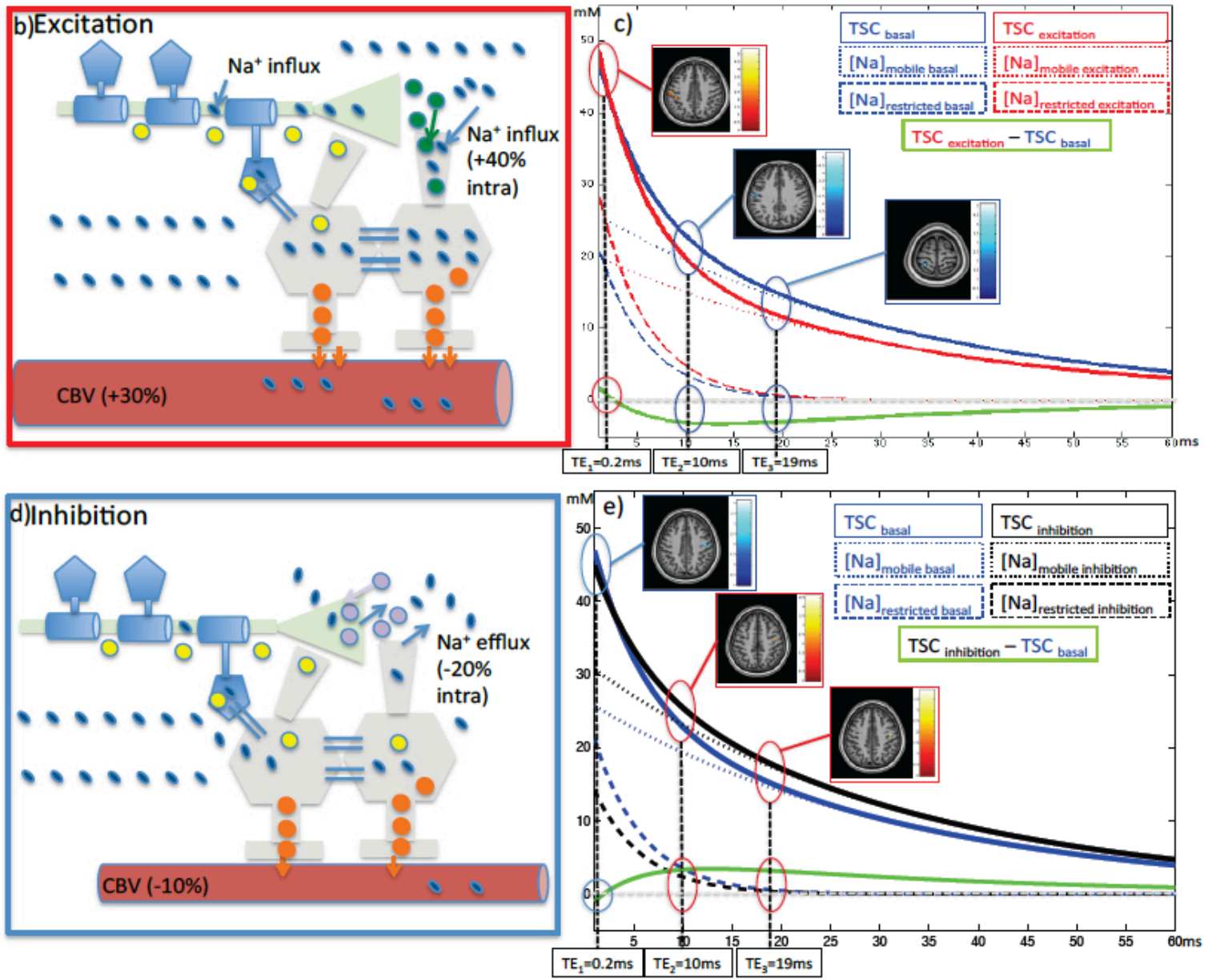

Supplemental Figure 6: TE dependencies of ${ }^{23} \mathrm{Na}$ MR signal decays for total, mobile and restricted pools of sodium in gray matter during basal period, excitation and inhibition and potential related phenomenons occurring within the neuro-glial-vascular ensemble.

a) Schematic representation of the neuro-glial-vascular ensemble during the resting period (adapted from Chatton et al., 2016)._b) Representation of the neuro-glial-vascular ensemble following activation with re-intake of glutamate by astrocytes is accompanied by $\mathrm{Na}$ influx into astrocytes and increase $\mathrm{CBV}$. These phenomenons may induce as shown in c) increase of ${ }^{23} \mathrm{Na}$ signal at $\mathrm{TE}_{1}=0.2 \mathrm{~ms}$ in relation with increase in $\mathrm{CBV}$, and decrease in ${ }^{23} \mathrm{Na}$ signals at $\mathrm{TE}_{2}$ and $\mathrm{TE}_{3}$ relative to the decrease in ${ }^{23} \mathrm{Na}$ signals of the mobile pools. d) Schematic representation of the neuro-glial-vascular ensemble following deactivation with $\mathrm{Na}$ eflux and decrease $\mathrm{CBV}$ that may induce e) decrease in ${ }^{23} \mathrm{Na}$ signal at $\mathrm{TE}_{1}$, and increase in ${ }^{23} \mathrm{Na}$ signals at $\mathrm{TE}_{2}$ and $\mathrm{TE}_{3}$ in the inhibited area.

Modeled curves were generated according to the following parameters: Basal period: $[\mathrm{TSC}]_{\text {basal }}=47 \mathrm{mM},[\mathrm{Na}]_{\text {mobile }}$ basal $\left.=26 \mathrm{mM},[\mathrm{Na}]_{\text {restricted-basal }}=21 \mathrm{mM}, \mathrm{T}_{2} *\left(\mathrm{Na}_{\text {mobile-basal }}\right)=31 \mathrm{~ms}, \mathrm{~T}_{2} *\left(\mathrm{Na}_{\text {restricted-basal }}\right)=5 \mathrm{~ms} ; \mathrm{a}\right)$ Excitation: $[\mathrm{TSC}]_{\text {activation }}=48 \mathrm{mM}$ $(+2.1 \%),[\mathrm{Na}]_{\text {mobile-activation }}=20 \mathrm{mM}(-30.0 \%),[\mathrm{Na}]_{\text {restricted-activation }}=28 \mathrm{mM}(+33.3 \%), \mathrm{T}_{2} *(\mathrm{Na}$ mobile-activation $)=31 \mathrm{~ms}, \mathrm{~T}_{2} *\left(\mathrm{Na}_{\text {restricted- }}\right.$ activation $)=5 \mathrm{~ms}$. Inhibition: $[\mathrm{TSC}]_{\text {Inhibition }}=46 \mathrm{mM}(-2.1 \%),[\mathrm{Na}]_{\text {mobile- Inhibition }}=29 \mathrm{mM}(+11.5 \%),[\mathrm{Na}]_{\text {restricted- Inhibition }}=17 \mathrm{mM}(-$ $19.0 \%), \mathrm{T}_{2} *\left(\mathrm{Na}_{\text {mobile- Inhibition }}\right)=31 \mathrm{~ms}, \mathrm{~T}_{2} *\left(\mathrm{Na}_{\text {restricted- Inhibition }}\right)=5 \mathrm{~ms}$. The green curves represented the functional ${ }^{23} \mathrm{Na}$ contrasts Note that the percentages of variations of sodium environments in the model are of the same order of those observed during experiments at $\mathrm{TE}_{1}$ and $\mathrm{TE}_{3}$. 